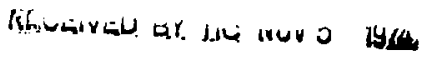

\title{
ATOMIC ELECTRONS SHAKE-OFF ACCOKPANYING ALPHA DECAY
}

\section{Contents}

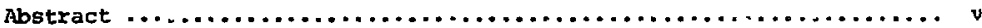

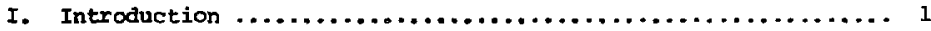

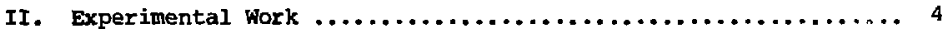

A. Alpha - $\mathrm{K} x$-Ray Coincidence Neasurement .............. 4

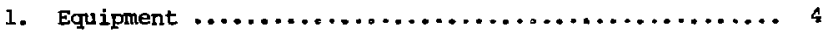

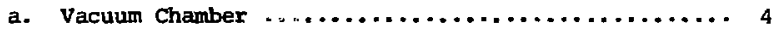

b. $\mathrm{K} x-\operatorname{Ray}$ side ............................ 5

c. $a$ side $\ldots \ldots \ldots \ldots \ldots \ldots \ldots \ldots \ldots \ldots \ldots \ldots \ldots \ldots \ldots \ldots \ldots \ldots \ldots$

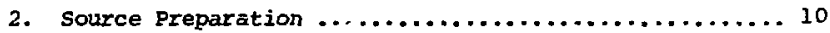

B. Alpha - I and $M x-r, y$ Coincidence Measurement ........ 12

1. Equipment $\ldots \ldots \ldots \ldots \ldots \ldots \ldots \ldots \ldots \ldots \ldots \ldots \ldots \ldots \ldots \ldots \ldots \ldots \ldots$

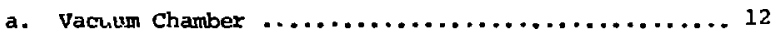

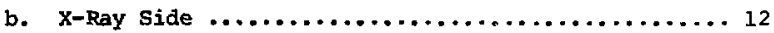

c. $\alpha$ side $\ldots \ldots \ldots \ldots \ldots \ldots \ldots \ldots \ldots \ldots \ldots \ldots \ldots \ldots \ldots \ldots \ldots$

2. Source Preparation ......................... 14

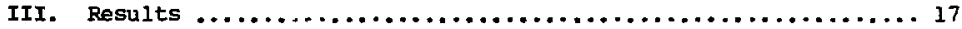

A. K Shell shake-off $\ldots \ldots \ldots \ldots \ldots \ldots \ldots \ldots \ldots \ldots \ldots \ldots \ldots \ldots \ldots \ldots$

1. ${ }^{238_{\mathrm{Pu}} \ldots \ldots \ldots \ldots \ldots \ldots \ldots \ldots \ldots \ldots \ldots \ldots \ldots \ldots \ldots \ldots \ldots \ldots \ldots \ldots \ldots \ldots \ldots \ldots \ldots}$

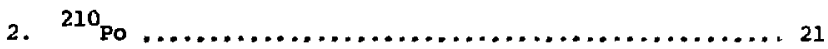

B. I and $M$ sbells shake-off $\ldots \ldots \ldots \ldots \ldots \ldots \ldots \ldots \ldots \ldots \ldots \ldots \ldots \ldots$

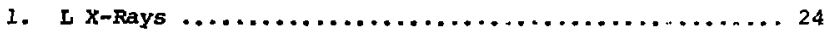

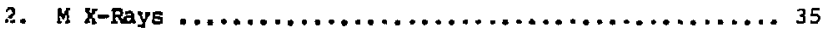

3. $\alpha$ sppctrum $\ldots \ldots \ldots \ldots \ldots \ldots \ldots \ldots \ldots \ldots \ldots \ldots \ldots \ldots \ldots \ldots \ldots \ldots \ldots \ldots \ldots$ 
IV. Theory and Discussion $\ldots \ldots \ldots \ldots \ldots \ldots \ldots \ldots \ldots \ldots \ldots \ldots \ldots \ldots$

v. summary and conclusions ........................ 55

References $\ldots \ldots \ldots \ldots \ldots \ldots \ldots \ldots \ldots \ldots \ldots \ldots \ldots \ldots \ldots \ldots \ldots \ldots \ldots \ldots \ldots \ldots \ldots \ldots \ldots \ldots \ldots \ldots . . .57$

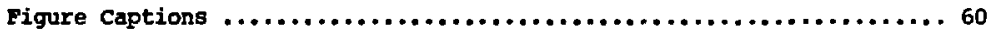

Acknowledgmentes $\ldots \ldots \ldots \ldots \ldots \ldots \ldots \ldots \ldots \ldots \ldots \ldots \ldots \ldots \ldots \ldots \ldots \ldots \ldots \ldots \ldots \ldots \ldots \ldots$ 


\section{ATOMIC ELECTRONS SHAKE-OFF \\ ACCOMPANYING ALPHA DECAY \\ Meir Shimshon Rapaport \\ Lawretuce Berkeley Laboratory \\ University of California \\ Berkeley, California 94720}

\section{ABSTRACT}

The $\alpha$ spectra associated with $\mathrm{K}$ - shell electron shake-off in 210 Po and ${ }^{238}$ Pu decay have been determined by $\mathrm{K} x$-ray - $\alpha$ coincidence measurements. Although the shapes of the spectra generally agree with theoretical expectations, some discrepancies are observed. From similar measurements the $\alpha$ spectra associated with $I$ and $M$ - shell electrons sirake-off in 210 po were determined. The abundances per $\alpha$ particle of the total $K, I$ and $M$ electron shake-off effects were determined in these measurements and found to be $P_{K}=(1.65 \pm 0.16) \times 10^{-6}, P_{L}=(7.23 \pm 0.55) \times 10^{-4}$

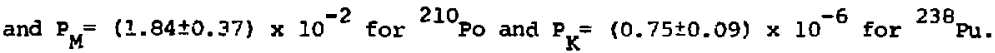
Also, the abundances per $\alpha$ particle of the $L$ subshell electron shake-off effecic were found to be $P_{L_{1}}=(5.11 \pm 0.40) \times 10^{-4}, P_{L_{2}}=(0.62 \pm 0.06) \times 10^{-4}$ and $P_{L_{3}}=(1.50 \pm 0.19) \times 10^{-4}$. Only limits on the ionizatiors probabilities of $\mathrm{M}$ subshells could be determined. These limits were: $\mathrm{F}_{\mathrm{M}_{2}}=7-2.38$, $P_{M_{4}} \div 248, P_{M_{5}}<178$ and $P_{M_{1}}+P_{M_{5}}>478$ of the total. These rasults are also compared with theoretical predictions. Further experimental and theoretical studies are suggested. 


\section{INTRODUCTION}

The phenomenon by which an electron in a given orbital is excited into the continuum (shake-off) during nuclear decay was first treated by Migdal ${ }^{1}$ and Feinberg ${ }^{2}$ and later by Levinger ${ }^{3}$ (all are perturbation type calculations). Since then much theoretical ${ }^{4-10}$ and experimental. ${ }^{11-17}$ work related to $\beta^{-}, \beta^{+}$and E.C. decay has been done. The various: experimental woxks involved measurements of $x-r$ ay $-\beta$ coincidences, $\beta$ and $x$-ray intensities, relative $x$-ray and $\gamma$-ray intensities and relative intensities of $x$-rays in parent and daughter nuclei. Shake-off of $L$ electrons accompanying internal conversion in the $k$-shell was also observed. $^{18}$ The agreenent between thenry and expeximent has in general been good. Recently, a distinctly different type of theoretical treatment of the shake-off phenomenon accompanying $\alpha$ decay was published by Hansen. 19

Essentially, all of the neasurements ${ }^{20-27}$ of electron shake-off during $\alpha$ decay have been made on ${ }^{210}$ Po with one unpublished result on ${ }^{238} \mathrm{Pu}$. In the ${ }^{210}$ Po experiments the $\mathrm{x}$-ray abundances were measured and any excess over that expected from the internal conversion of the 803 KeV $Y$-ray was assumed to be due to alectron shake-off. The measurement of the $\mathrm{K}$-shell effect in ${ }^{238} \mathrm{Pu}$ decay was very similar, but more involved because of additional gamma rays.

The $\mathrm{K}$-shell effect was studied ${ }^{20-23}$ by measuring the radiation of 210 Po using proportional counters or NaI scintillation counters and the radiation was easily est:ablished to be lead $\mathrm{k} x$-rays。 The agreement between experiment and perturbation type theory has not been good. Gener- 
ally, the experimental results for the $K$ shell probability were about 608 of the theoretical predictions, and the discrepancy was about twice the stated experimental exror. On the other hand, Hansen's theoretical predictions of $K$ shell lonization are in good agreement with experiment. Several measurements of the total shake-off phenomenon in the $\mathrm{L}$ and shell exist. Curie and Joliot ${ }^{24}$ were the first to observe the soft radiation associated with alpha decay of ${ }^{210}$ po. They detected the photons by means of an ionization chamber connected to an electroscope and Idontified photon energies by absorption coefficients. They believed the radiation to be po x-rays excited by $\alpha$ particles. However, they stated that their techrique could not distinguish between lead and polonium photons. Riou ${ }^{25}$ identified the $I$ x-rays associated with $210^{\text {po alpha }}$ decay as lead x-rays. He used a Geiger-kïller detector and identified the soft radiation by selective absorption coefficients. Rubinson and Bernstein ${ }^{26}$ and leter Rubinson ${ }^{27}$ studied the $L$ and $M$ x-rays respectively. They uged a proportional counter und were able to observe some of the structure associated with filling the vacancies in the $L$ and $M$ shells. The discrepancy between experiments and perturbation type theory is very large. Again, Hansen's theoretical predictions are in good agreement with experiment.

A different kind of experimental evidence of the shake-off phenomenon is the charge diatribution of the recoiling daughter atoms after alpha decay. The charge distributions of several alpha emitters were studied 29-33 and they varied fros -1 to +10 in the absence of internal conversion. 
Approximately 90 of the recolling atoms carried zero or +1 charge and the mean charge was less than Is However, these charge distributions were due mostly to outer shell electron ionization rather than $K, L$ and $M$ shells.

The present work (with high resolution solid state detectors) was undertaken to measure directly that part of the alpha spectrum connected with the eleatron shake-off effect in the $\mathrm{K}\left(^{210}\right.$ Po and ${ }^{238} \mathrm{Pu}$ sources) and the $I$ and $M\left({ }^{210}\right.$ po source) shells. In the same time the differential shape of this spectrum was to be determined and the results compared with theoretical predictions. Also, the initial I subshell vacancies and the $y$ ields of $K$ and $M x$-rays that result from the shake-off effect were to be determined. 


\section{EXPERIMENTAL MORK}

The general experimental procedure was to measure the energy and abundances of the alpha spectrum wich was in coincidence with $\mathrm{K}, \mathrm{L}$ and $M$ x-rays as we $I 1$ as the energies and abundances of the $I$ and $M x$-rays. Two alpha emitters, ${ }^{210}$ Po and ${ }^{238} \mathrm{Pu}$, were studied. The shake-off effect

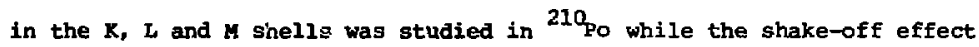
accompanying the $\alpha$ decay or ${ }^{238} \mathrm{P} u$ was studied only in the $\mathrm{K}$ shell.

Twe different experimental systems were used. One system was utilined to measure the $\mathrm{k}$. shell effect and the second system was utilized to measure the shake-off effect in the $I$ and $M$ shells. The two systems are described in the following sections.

The coincidence systems were assembled with the following objectives in mind: (1) obtain the largest geometry factor possible for the x-ray detectors; (2) reduce the background radiation detected by the x-ray detectors as much as possible to make the rate of accidental coincidences acceptable; and (3) maintain adequate $\alpha$ detector resolution In spite of the Intense $\alpha$ radiation.

\section{A. Alpha - K X-Ray Coincidence Measurement}

\section{Equipment}

\section{a. Vacuun Chamber}

The $x$-ray detector hous'ng was positioned at one end of a cylindrical aluminum vacuun chamber 3.5 inches long and 2.0 inches inside diameter. The a detector housing penetrated the vacuum chamber from the 
opposite side. The position of the a detector was mechanically controlled from outside the vacuum chamber and the $\alpha$ detector could be positioned anywhere between the two ends of the vacuum chamber. The source to be studied was mounted on a thin lucite ring which was then attached to the face of the $x$-ray detector housing. Thus, the source-to-detector distance was variable for the $\alpha$ side but not for the $x$-ray side. When a coincidence experiment was not in progress, a mechanically controlled aluminum foil could be placed between the souxce and the $\alpha$ detector to protect the latter from the interse $\alpha$ radiation.

An oil pump was used to evacuate the vacuum chamber. A cold trap (dry ice + alcohol) was cornected to the pumping line to prevent the oil from coating the a detector.

\section{b. K X-Ray Side}

The $\mathrm{K}$ x-rays were detected with a solid state detector of pure Ge which had a thin aluminum window. The detector had a full-width-athalf-maximum (F-W-H-M) of $1.0 \mathrm{KeV}$ for a $122 \mathrm{KeV} \gamma$-ray and an overall detection efficiency of 13.58 at that energy. To determine the efficiency curve, $\gamma$ rays in standard efficiency sources of known disinteg:-ation rates were measured. The standard sources were: ${ }^{241} \mathrm{Am},{ }^{203} \mathrm{Hg},{ }^{57} \mathrm{Co}$, $22 \mathrm{Na},{ }^{137} \mathrm{Cs}$ and ${ }^{54} \mathrm{Mn}$.

The detector's output was amplified and fed into a singel channel analyzer (see Fig̣. 1). In the ${ }^{210}$ Po measurement, this alayzer was set on the $\mathrm{K}_{\alpha} \mathrm{x}$-rays, which comprise 788 of the total. Figure 2 shows the photon radiation between $20 \mathrm{KeV}$ and $150 \mathrm{KeV}$. The marked area shows the 
energy region that the gingle channei analyzer was set on. In the ${ }^{238}{ }_{\mathrm{Pu}}$ measurement, however, the single channel analyzer was set on the $k_{\beta}$ $\mathrm{x}$-rays, which are only $238^{34}$ of the total $\mathrm{K} x$-rays, in order to eliminate the $\alpha$ spectrum in coincidence with the $100 \mathrm{KeV} \gamma$-ray. Figure 3 shows the photon radiation between $35 \mathrm{KeV}$ and $180 \mathrm{KeV}$. Again, the marked area shows the energy region that the single channel analyzer was set on. In this lattex experiment the $\gamma$-ray output of the preamplifier was gain-atabilized. The output of the single channel analyzer was part of a fast-slow triple coincidence systen. The block diagram is shown in Fig. 1.

\section{c. $\underline{\alpha}$ side}

The $\alpha$ particles were detected with Au-Si surface barrier type detectors (12 mu in diameter) with geometries of about 2-3\%. The intense bombardment of the detector by the $\alpha$ activity of the sources resulted in a deterioration of resolution over the course of the experiments. In the ${ }^{210}$ Po measurement the F-F-H-H changed from $22.5 \mathrm{KeV}$ at the beginning of the experiment to $30.0 \mathrm{keV}$ at the end. For the ${ }^{238} \mathrm{Pu}$ measurement the F-W-H-M changed from 30.0 to $36.5 \mathrm{KeV}$.

The $\alpha$ detector output was first sent to a gain-stabilizer. Then part of the output was fed into the triple coincidence system, part was fed into a unit which scaled down the counting rate by a factor of 20 and part was fed to a 400 channel pulse height analyzer through a bias anplifier and a linear gate. The linear gate was triggered via a mixer gate by either pulses from the triple coincidence system or tive scinled- 


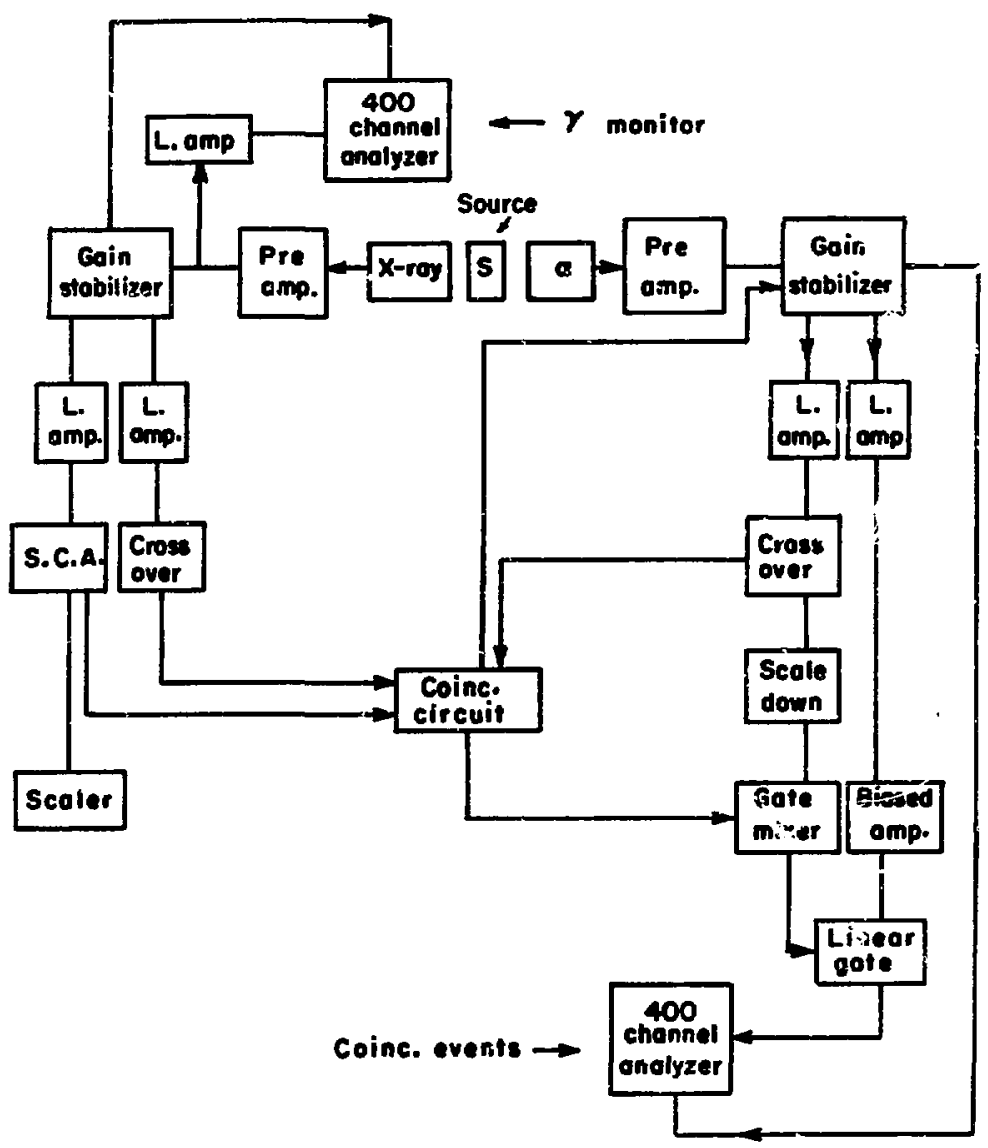

XEL744-2822

Fig. 1 


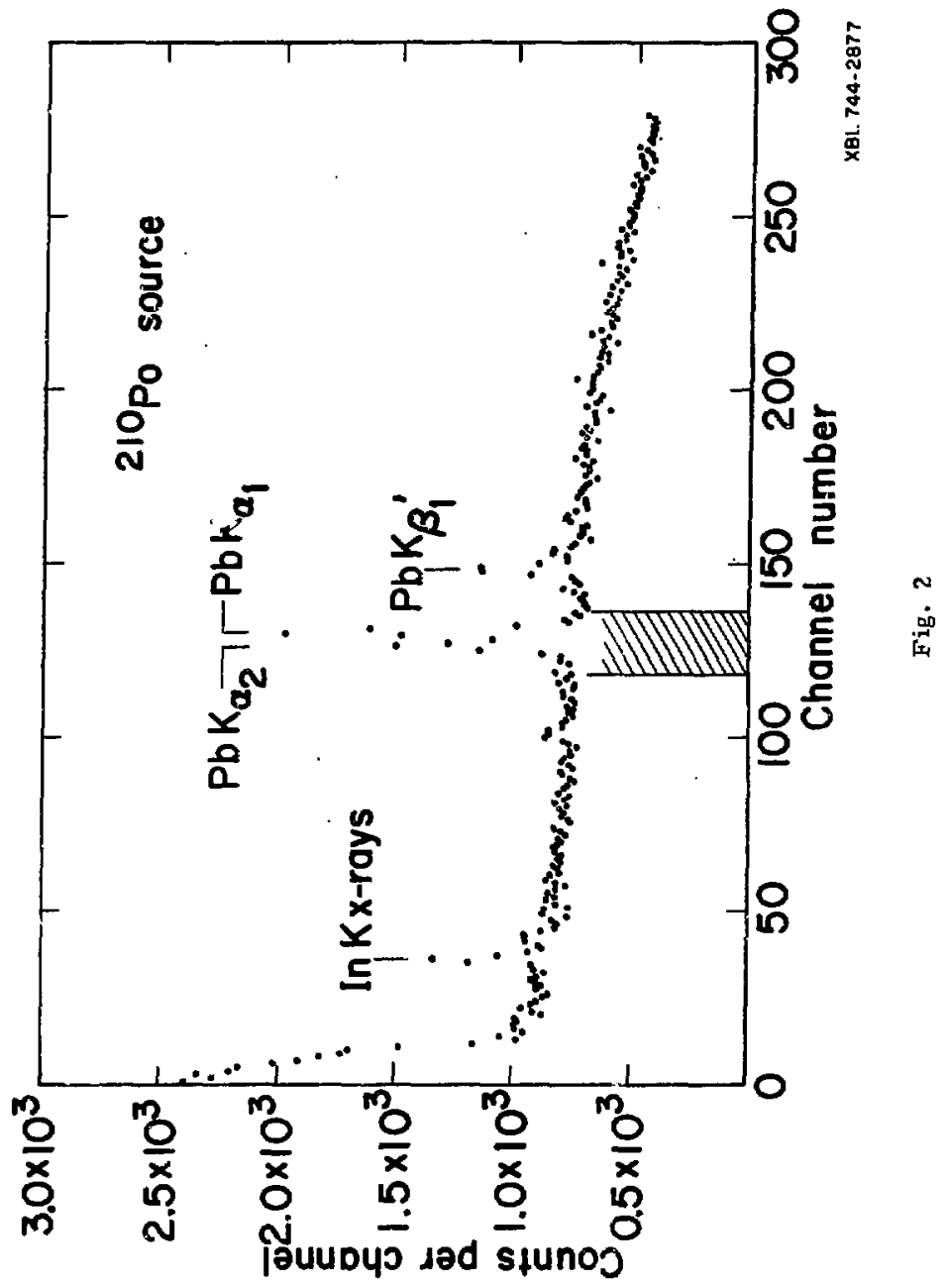


Counts per channel

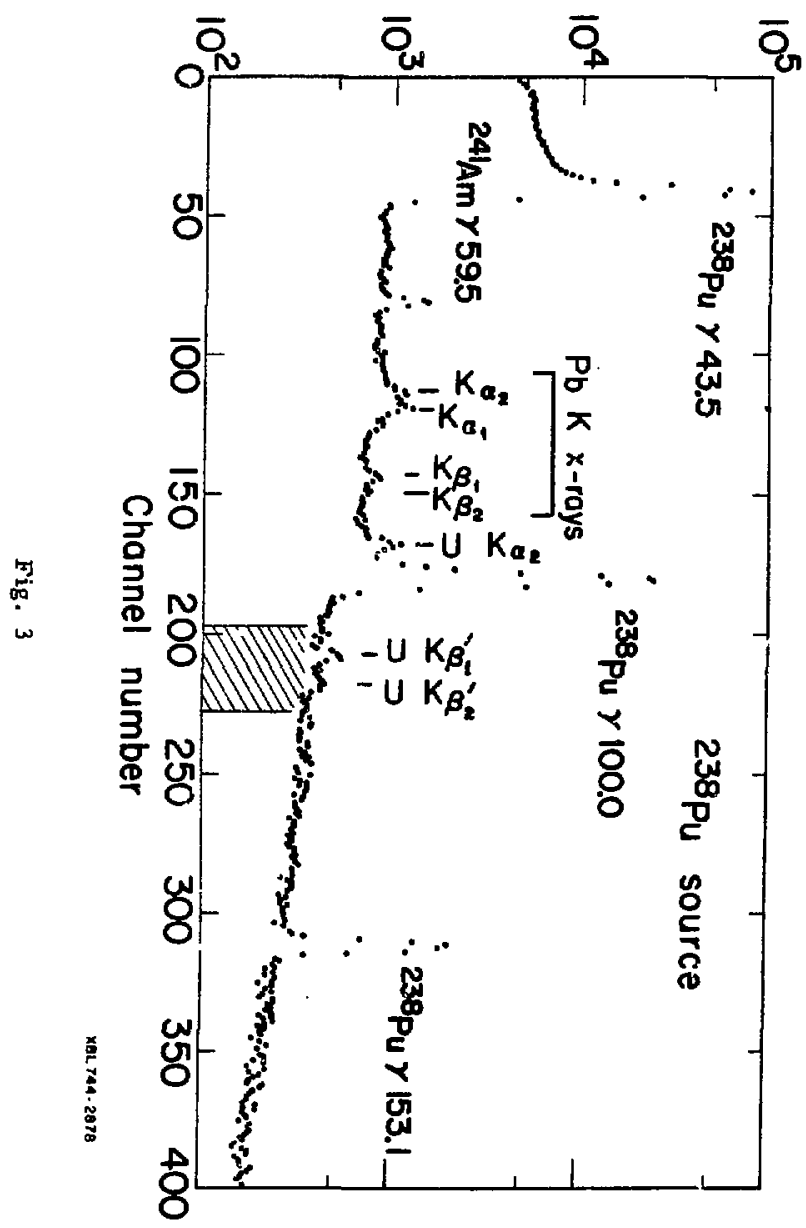


down $s$ singles pulses. The pulse height analyzer was also gated by the triple colncidence system $v^{3}$ a the gain-stabilizer so that only coincidence pulses were stored and not the scaled-down singles used for gain stabilization.

The net effect of the electronic arrangement was that $\alpha$ pulses which were in coincidence with the $\mathrm{K} x$-ray gate could register on the pulse height analyzer with a minimum of accidental coincidences $172 \times 10^{-9}$ sec resolving time) and without any gain ehange during the experiment.

The whole system was enclosed in walls made of lead bricks. These served to reduce the background radiation detected by the $x$-ray detector and hence reduced the probability of accidental coincidences. than the Fo source was studied additional steel bricks and aluminum plateg were placed against the lead brick walls. They prevented any lead $x$-rays excited in the lead bricks from reaching the $x$-ray detector.

\section{Source Preparation}

The ${ }^{238} \mathrm{pu}$ was chemically purified by dissolving in $12 \mathrm{M} \mathrm{HCl}$, loading onto an anion column (DOWEX AG 1x8\%), washing the column with $12 \mathrm{MHCi}$ containing some $\mathrm{HNO}_{3}$ and eluting the ${ }^{238} \mathrm{Pu}$ off the column with a solution of $12 \mathrm{M}$ in HCl and $.44 \mathrm{M}$ in $\mathrm{HI}$. The eluent was evaporated to dryness and then vaporized in vacuum from a tungsten filament onto a .002 inch thick mylar foil. The source which had been collimated to an area 5/16 inch in diameter during vaporization was invisible and had an activity of $\sim 1.2 \times 10^{7} \alpha \mathrm{dis} / \mathrm{min}$. The ${ }^{238}$ Pu source was of high purlty as is indicated in Fig. 3 。 
But for the $\gamma$ rays associated with the decay of ${ }^{238} \mathrm{Fu}$, uranium $x$-rays were obgerved. They originated from the intemal conversion of the 153.1 KeV $\gamma$-rays and the shake-off phenomenon. In addition, the $59.5 \mathrm{KeV}$ Y-rays associated with the decay of ${ }^{241}$ An were observed. Part of the latter activity was due to ${ }^{241} \mathrm{Am}$ impurity in the source and part was due to ${ }^{241}$ Am activity that: scattered in the vacuum chamber curing the calibration of the system. Also observed were lead $\mathrm{x} x$-risys which were excited in the lead brick wall that surroundes the whole systen and then detected in the $x$-ray detector.

Two vials of ${ }^{210}$ Po were purchased from New England Nuclear. The $210_{p o}$ was catalogued as carrier-free and of natural origin although investigation at the conclusion of the experiment showed it was prepared by the reaction and decay: ${ }^{209} \mathrm{Bi}(\mathrm{n}, \gamma){ }^{210} \mathrm{Bi} \frac{\beta-}{5 \mathrm{daY}}{ }^{210} \mathrm{Po}$. The ${ }^{210} \mathrm{Po}$ from one of the vials was further purified by fuming to near drymess with concentrated $\mathrm{HWO}_{3}$ loading onto a cation colum (DOWEX 50) with .2 M HCl, washing with $2 \mathrm{M} \mathrm{HNO}_{3}$ and eluting the $210_{\mathrm{PO}}$ with $2 \mathrm{M} \mathrm{HCl.} \mathrm{The} \mathrm{overall}$ yield of the above procedure was $\sim 208$. The eluent was evaporated to dryness and vaporized like the ${ }^{238}$ pu onto a .002 inch thick mylir foil. The source was $\sim 1.7 \times 10^{7} \alpha$ dis/min and was invisible. The ${ }^{210}$ po source was very pure as is indicated in Fig. 2. Except for lead $\mathrm{x}$-rays only Indium $\mathrm{k} x$-rays were observed. The latter originated from the indium firil which was part of the $x$-ray detector. 


\section{B. Alpha - L and M X-Ray Coincidence Measurement}

\section{Equipment}

\section{a. Vacusum Chamber}

The $x$-ray detector housing was positioned at about the center of a cublc (5.5 inch in dimengion) aluminum vacuum chamber. The housing had a .001 inch thiek beryllium window which could be opened once a good vacuum was established in the chamber. A motor driven $\alpha$ detector penetrated the vacuum chamber from the side opposite the $x$-ray detector. The sources to be studied were mounted on the $\alpha$ detector housing about 1 on away from the $\alpha$ crystal and could be brought within $3 \mathrm{~mm}$ of the face of the x-ray crystal. The source-to-detector distance was variable for the $x$-ray side but not for the $\alpha$ side. When a coincidence experiment was not in progress, a magnetically controlled nickel foil could be placed between the source and the $\alpha$ detector to protect the latter from the intense $\alpha$ radiation.

A cyrogenic punp, two 8 liter ion pumps and 2 cold finger were used to evacuate the vacuum chamber. On the average 6 hours of pumping were needed before a pressure of $\sim 10^{-m}$ um of $\mathrm{Hg}$ was reached and the berylliur: window on the face of the $x$-ray detector housing could be opened.

\section{b. $x-$ kay side}

The $x$-rays were detected with a SI(LI) solid state detector which was 5 num in dimmeter and $3 \mathrm{~mm}$ thick. The detector had a fullwidth-at-half-maximum (F-Wm-H-M) of $180 \mathrm{eV}$ for $6.46 \mathrm{KeV}$ iron $\mathrm{K}$ x-rays. 
In the experimental arrangement the maximum overall detection efficiency (which includes the geometry of the system) was 6.08 for $10 \mathrm{keV}$ radiation and at $3.3 \mathrm{KeV}$ this was reduced to $2.55 \%$,

To determine these efficiencies ${ }^{241} \mathrm{Am},{ }^{57} \mathrm{Co},{ }^{65} \mathrm{Zn}$ and ${ }^{54} \mathrm{Mn}$ were separately vaporlzed in vacuum from tunggten filaments onto .001 inch thick beryllium disks. : se sources were collimated to an area 2 um in diareter during vaparization. The absolute disintegration rate of the sourceg were determined by measuring the abundances of their $r$-rays and comparing them with known standards of the same isotopes. Tabulated $^{35-37}$ values of the intensities of $x$-rays and low energy $\gamma$-rays associated with the above sources were then used to determine the $x$-ray detector efficiency curve.

The preamplifier utilized a low-noise field-effect transistor at low temperature wish pulsed optical feedback. Final amplification was accomplished by an Anplifier System Nodule ${ }^{38}$ which contained a linear amplifier (17 $\mu$ sec time constant), a biased amplifier and a pileup rejector. The output was fed both into a coincidence circuit and into an analog-to-digital converter (A.D.C.) which fed a two parameter coincidence system. The block diagram for the system is shown in Fig. 4. The linearity of the anplifler-analyzer system for $x$-rays was better than .36 and no shift in energy was observed in the 5 months of experiments.

\section{c. $\alpha$ side}

The $\alpha$ particles were detected with a Au-Si surface-barrier type 
crystal (6 m in diamoter) with a geometry of, 808 and resolution of $20.0 \mathrm{keV}(F-W-H-H)$. The $\alpha$ detector was operated at $4^{\circ} \mathrm{C}$, and no deterloration of its resolution was observed during the experinents although the pulse amplitude gradually decreased with time. The energy linearity of the amplifier-analyzer aystem for $\alpha$ particles was better than $.5 \%$ in the region of interest.

The $\alpha$ detector output was amplified and then fed both into the coincidence circuit and into a separate A.D.C. The output from this A.D.C. was fed into a gain stabilizer, which operated only on those pulses that were in coinclaence with $x$-ray pulses. After 8 days of operation the gain stabilizer was not able to compensate for the decreasing preamplifier output and the pulse height out of the amplifier also began gradually decreasing. The pulses from both the $x$-ray side and $\alpha$ side A.D.C." $\mathrm{s}$ were routed into a two parameter coincidence system as shown in Fig. 4. The data was reduced with the computer program MUITI ${ }^{39}$

\section{Source Preparation}

The ${ }^{210}$ po was of the same origin as the ${ }^{210}$ po uzed in the $K$ shell measurements. In addition to the ${ }^{210}$ Po $803 \mathrm{KeV} \mathrm{Y-ray,} \mathrm{Low}$ intensity Ea $\mathrm{K} \times$-rays were observed as well as the ${ }^{210} \mathrm{~Pb} 47 \mathrm{KeV} \mathrm{Y}-\mathrm{ray}$. Since the above radiations do not interfere with the experiments the 210 po was not further purified.

The ${ }^{210}$ Po activity was vaporized in vacuum from a tungsten filament onte a .001 inch thick beryllium disk in exactly the same way 


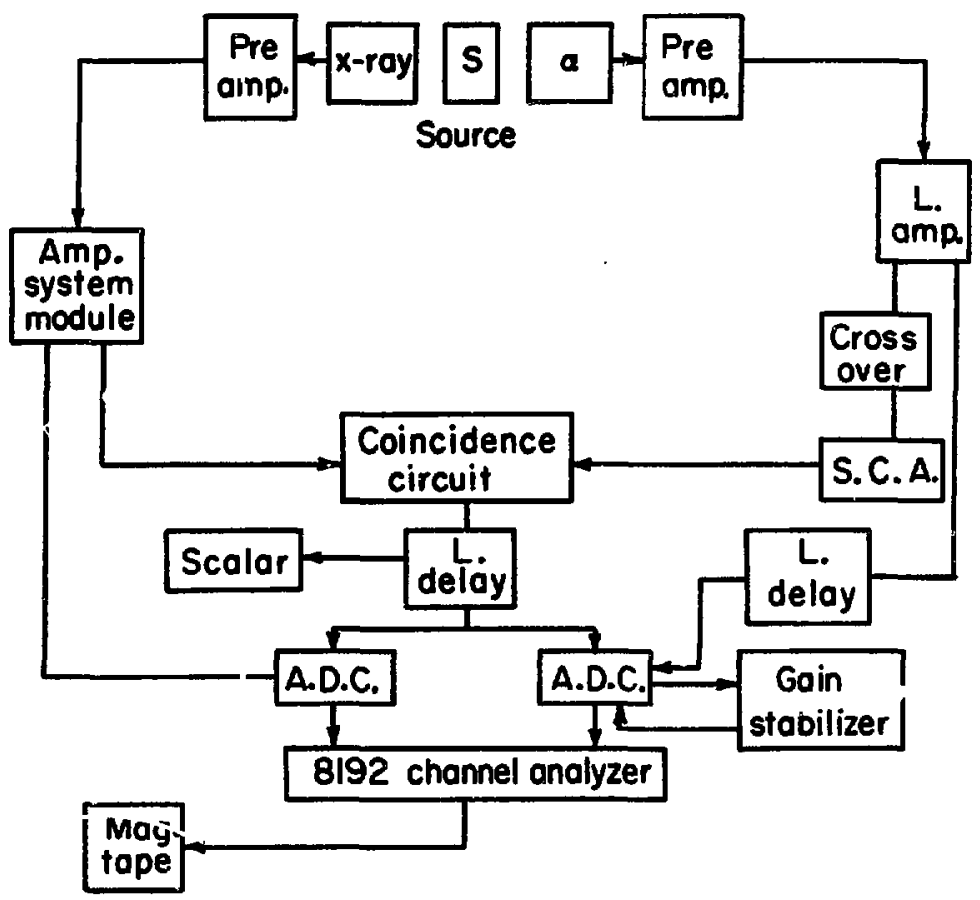

XEL 747-3663 
as in the efflclency determinations. The latter was thick enough to stop any of the a particles from reaching the $x$-ray detector. The source, which had been collimated to an area $2 \mathrm{~km}$ in diancter during vaporization, had activity of $i 2.6 \times 10^{6} \mathrm{a}$ dis/min. 
III. RESULTS

A. K Shej.1 Shake: if

1. $238_{\text {Pu }}$

The ${ }^{238} \mathrm{Pu}$ wa measured in the colncidence unit for a total running tive of 15 days. The singles apectra were measured and recorded every day ae ware the coincident spectra. The $Y$ singles spectra were monitored contimously. The $\alpha-k x-r w y$ coindicnece spectra for the ons day runs were summed and this total spectrum is presented in Fig. 5. The abscissa is the analyzer channel in whict. the colncidences appeared, and it is roughly linear with the a particle energy. The ordinate is the total number of observed coincidences in the 15 days periol. The highest energy peaks, $\alpha_{0}$ and $\alpha_{44}$, are due to accidental coincidences between the most intense $\alpha$ groups and radiation in the $k x$-ray gate. The most Intense peak, $\alpha_{296}$, is due to true colncidences with $\mathrm{K} \times$-rays from conversion of the $153 \mathrm{KeV} \gamma$-ray and with the compton background of this $Y$-ray in the $K x$-ray gate region. The pertinent part of the ${ }^{238} \mathrm{Pu}$ decay scheme is shown in Fig. 6.

The $\alpha_{296}$ coincident peak (see Fig. 5) is broader than the $\alpha_{0}$ and $\alpha_{44}$ accidental peaks and this is probably due to a combination of effects including shifts in the threshold of the bias amplifier and a non-linearity in this region of the pulse height analyzer. The broad $\alpha$ distribution (see Pig. 5) in the region of channels 175-260 is broader than $\alpha_{296}$, talls substantially more on the low energy side and, if the shake-off effect is excluded, would not correspond to any $\alpha$ groups of 
Coincidences per channel

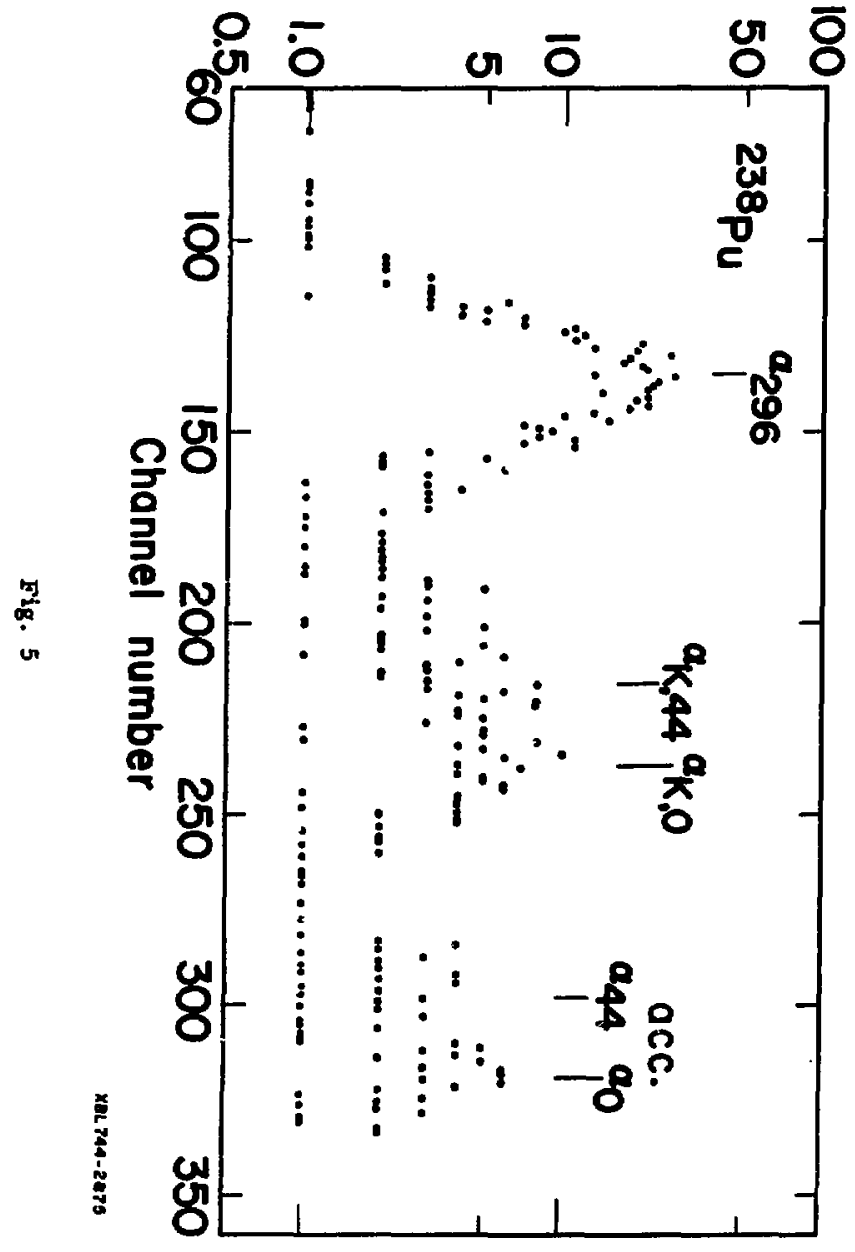




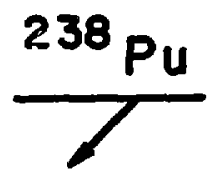

Energy

(keV)

$0.005 \%$

296.6

$1.0 \times 10^{-3} \%$

E2

$143.5-\frac{1}{7.4 \times 10^{-3} \%}$

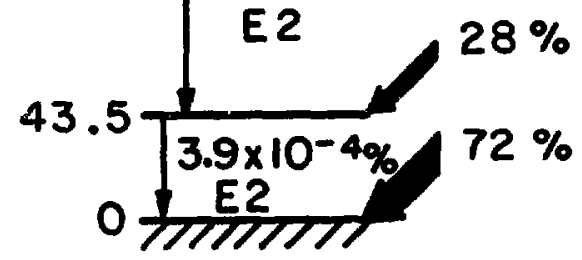

$234 U$

XEL744-2823 
${ }^{238} \mathrm{Pu}$ expected to be in coincidence with the $\mathrm{K}_{B} \mathrm{x}$-ray gate, A measureserit was made of the maximum amount of the 100 thev $Y$-gate of ${ }^{238_{3 u}}$ which could be in the gate region. It indicated that only a negligible proportion of the colnoidences in the region of channels 175-260, could be due to this $y$-ray. To determine if these observed coincidences had the proper maximm energy for a ${ }^{238} \mathrm{Pu} \alpha_{0}$ particle which ejected a $\mathrm{K}$ electron with about zero kinetic energy their high energy side (see Fig. 5) and that of ${ }^{238} \mathrm{Pu} \alpha_{0}$ was extrapolated to $\sim 1 / 4$ of their peak helght. There was a difference in energy of $115 \pm 10 \mathrm{keV}$ which agreas with the $x$ binding energy of uranium, $115.6 \mathrm{kev}$.

Thus, the distribution in Fig. 5 in the region of channel 175260 should be due to the electron shake-off effect of the main alphr. Groups. The distribution is spread out over so many channels because there are wo major $\alpha$ groups involved, $\alpha_{0}$ and $\alpha_{44}$, and because the sineke-off electrong carry off energy causing a spread in $\alpha$ particle energy and a tailing on the low energy side. There was a total of 271 coincidences $(\sim 264$ and $\sim 7$ accidentals) measured in the 15 day experiment in the region of interest (channel 175-260). From the true coincidence counting rate, the $\alpha$ singles counting rate, the $\mathrm{K} x$-ray side detector efficiency (including geometry), the fraction of total $\mathrm{K} x$-rays in the gate and the $K$ shell fluorescence $y$ ield, the abundance of ejected $K$ shell electrons is $(0.75 \pm 0.09) \times 10^{-6}$ per ${ }^{238}$ Pu a particle. The nomenclature for the normal a groups shown in Fig. 5 is the usual one with the energy of the excited state being a subscript to the 
a symbol, e.g., the ${ }^{238} \mathrm{Fu}$ a grolus populating the $44 \mathrm{KeV}$ axcited stite in ${ }^{234} \mathrm{U}$ is designated ${ }^{23 B_{P u}} \alpha_{44}$ or simply $\alpha_{44^{\circ}}$. I suggest for the $\alpha$ groups ejecting orbital electrons in their passage through the coulomb field, that the ahell designation of the ejected electrons be added as a subscript before the excited state energy. Thus, the ${ }^{238} \mathrm{Pu} \alpha$ group which populates the $44 \mathrm{KeV}$ state in ${ }^{234} \mathrm{U}$ and which also causes a $\mathrm{K}$ electron to be ejecced would be designated ${ }^{238} \mathrm{Pu} \alpha_{K, 44}$ or simply $\alpha_{K, 44^{\circ}}$ 2. 210 PO

The ${ }^{210}$ Po was also neasured in the coincidence unit for a total running time of 15 days. The experiment was very similar: to that for ${ }^{238} \mathrm{Pu}$ exsept that a larger fraction of the $\mathrm{x} x$-ray peak could be used in the gate as there are no gavma rays in ${ }^{210}$ Po decay near the gate energy. The various colncidence runs in the 15 day period were sumed and the total spsctrum 1 s shown in Fig. 7. The highest energy paak, $\alpha_{0}$, is tue to accidental coincidences with the main a group. The only

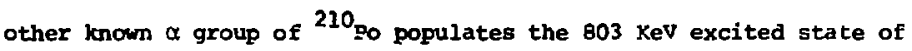
${ }^{206} \mathrm{~Pb}$ and has a very low abyidance 40 of $1.0 ? \times 10^{-5}$. The pesk at $v$ channel 340 (see Fig. 7 ) is broader than $\alpha_{0}$ and taijs more o: the low energy side.

The linearity of the amplifier-analyzex system for particles was carefully checked with ${ }^{240} \mathrm{Pu}$ and ${ }^{242} \mathrm{Pu}$ and was found to be lineac within 18 in the region of interest. Thus, the increased peak width is not due to non-linearity in the energy scale and is very likely caused by the kinetic energy carried off by the $k$ electrons ejected during the 


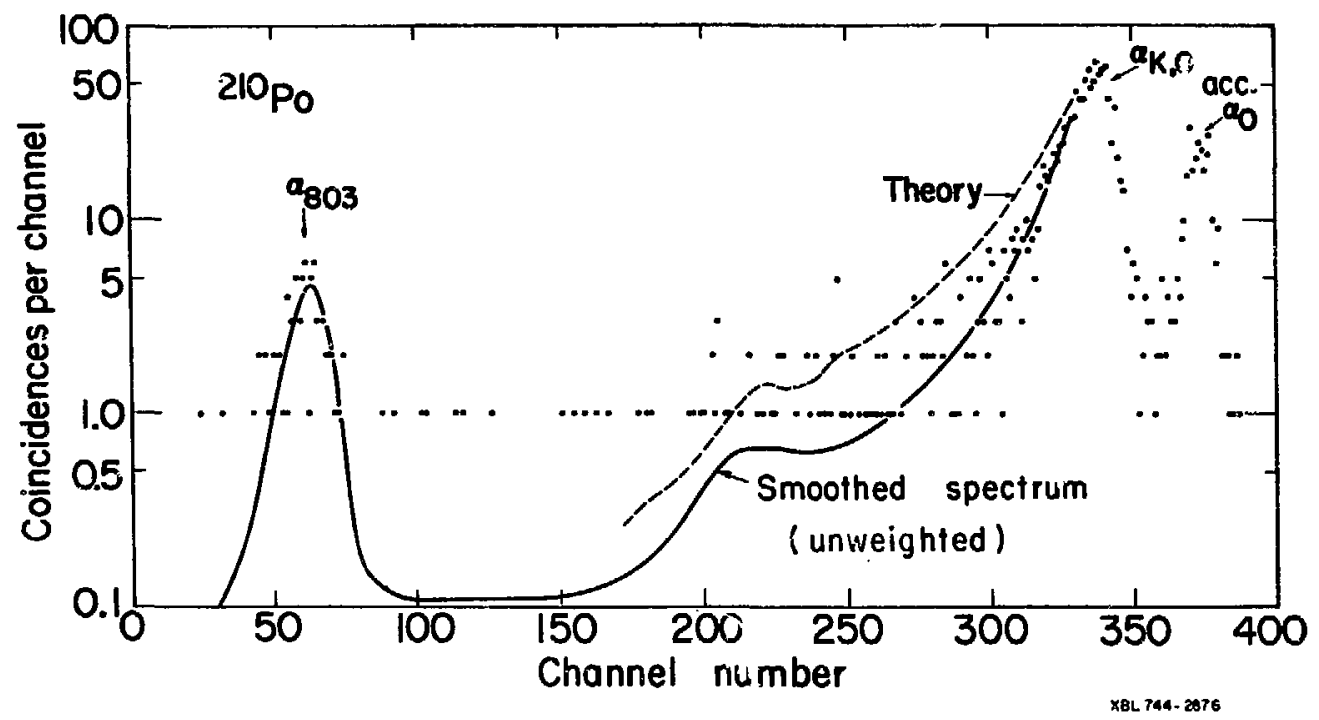

Fig. 7 
$\alpha$ decay process as in ${ }^{238}$ pu decay. By extrapolating the two peaks (see Fig. 7) in the same fashton as for the ${ }^{238} \mathrm{Pu}$ experiment, a difference In energ; of $88 \pm 1 \mathrm{KeV}$ was found in excellent agreement with $\mathrm{K}$ shell binding energy of lead, $88.0 \mathrm{KeV}$.

There was a total of 1,347 coincidences $\curvearrowright 1,285$ true and $\sim 62$ accidental) in the region of the $\alpha$ shake-off peak, 2?-0 Po $\alpha_{K, 0}$. CaIculated in the same way as for the ${ }^{238} \mathrm{Pu}$ experiment the abundance of ejected $K$ shell electrons is $(1.65 \pm .16) \times 10^{-6}$ per ${ }^{210}$ Po $\alpha$ particle. As a check on the correctness of the geometry calibration, the $k$ conversion coefficient of $\alpha_{803}$ was calculated from its abundance in the coincidence run (see Fig. 7) and the tabulated sirgles abundance, $1.07 \times 10^{-5}$. The resulting value $(8.1 \pm 1.4) \times 10^{-3}$ is in good agreement with the theoretical $^{41} \mathrm{E} 2 \mathrm{~K}$ conversion coefficient, $8.08 \times 10^{-3}$.

\section{B. I and $M$ Shells Shake-Off \\ The ${ }^{210}$ Po source was measured in the coincidence unit for a} total of 13.3 days during the 14 day experiment. The $\alpha$ singles spectra were measured and recorded on magnetic tape every day as were the coincidence spectra. The spectrum of $\mathrm{L} x$-rays in coincidence with $\alpha$ particles 1s shown in Fig. 8. In Fig. 9 are shown the coincident $M$-rays for the same measurement. A 2.9 day $x$-ray singles measurement was also made, and the $M$-ray region 18 shown in Fig. 10. The intensities of the $I_{\alpha}$ peaks In the singles and coincidence runs agreed within 28 which indicated the coincidence efficiency was close to 100\%, The $\alpha$ spectra in coincldence with $I x$-rays and $M x$-rays are shown in Fig. $11(a-e)$ for 
8 days of measurement.

\section{I X-Fays}

Figure 8 shows the photon radiation between $9.3 \mathrm{KeV}$ and 28.3 Kev in coincidence with ${ }^{210}$ Po a particies. Characteristic lead I $x$-rays are observed as well as impurity $x$-rays from ${ }^{241}$ Am near the detector. The $\mathrm{L}_{\alpha}$ peak arises from $\mathrm{L}_{3}$ vacancy filling, the $\mathrm{L}_{\beta}$ peaks arise from all three subshells and the $I_{\gamma}$ peaks arise from $I_{1}$ and $I_{2}$ subshells. A spectroscopic diagram of the radiative transitions that comprise the characteristic lead I x-rays is given in Fig. 12.

From the total number of coincidences in a given peak show. in Fig. 8 and the $x$-ray detector efficiency curve, the following two ratios were found: $\mathrm{P}_{\mathrm{L}_{\alpha}} / \mathrm{P}_{\mathrm{L}_{\mathrm{B}}}=1.14 \pm . .06, \mathrm{P}_{\mathrm{L}_{\alpha}} / \mathrm{P}_{\mathrm{L}_{Y}}=5.18 \pm .26$. In addition the ratio $P_{I_{\alpha}} / P_{I_{\ell}}=20.0 \pm 4.0$ was determined from the singles spectrum (not shown since it is similar in shape to the coincidence spectrum but with a larger number of counts registered, because the nimber of $I_{\ell}$ events was too low in the colncidence measurement. ${ }^{P_{L_{\alpha}}}$, for example, is the probability par particle of emitting an $\mathrm{L} x$-ray belonging to the $L_{\alpha}$ peak. From the total number of events in a given puak, the efficiency curve and the $\alpha$ singles counting rate the following abundances were obtained: $\quad P_{L_{\alpha}}=(1.11 \pm .11) \times 10^{-4}, P_{L_{B}}=(9.72 \pm .78) \times 10^{-5}$, $P_{L_{Y}}=(2: 15 \pm .32) \times 10^{-5}, P_{I_{\ell}}=(1.11 \pm .22) \times 10^{-6}$. In the above, accidental coincidences and scattered ralliation were ignored since their contributicn was negligible.

The Probabilities $\mathrm{P}_{\mathrm{L}_{\alpha}}, \mathrm{P}_{\mathrm{L}_{\beta}}$, etc. can be written in terms of $\mathrm{P}_{\mathrm{L}_{1}}$, 


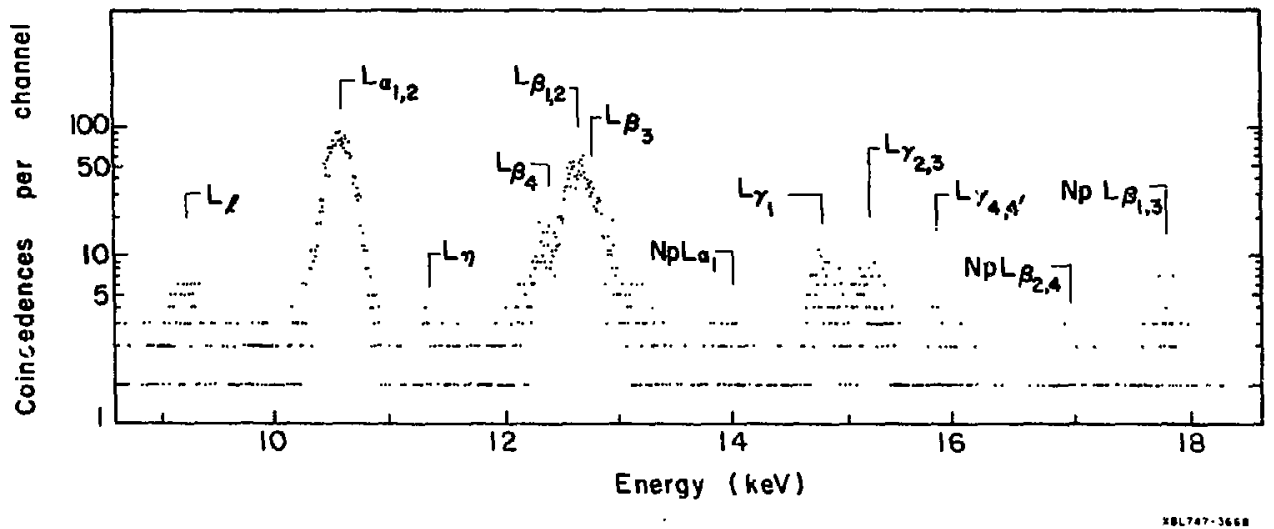

Fig. 8 


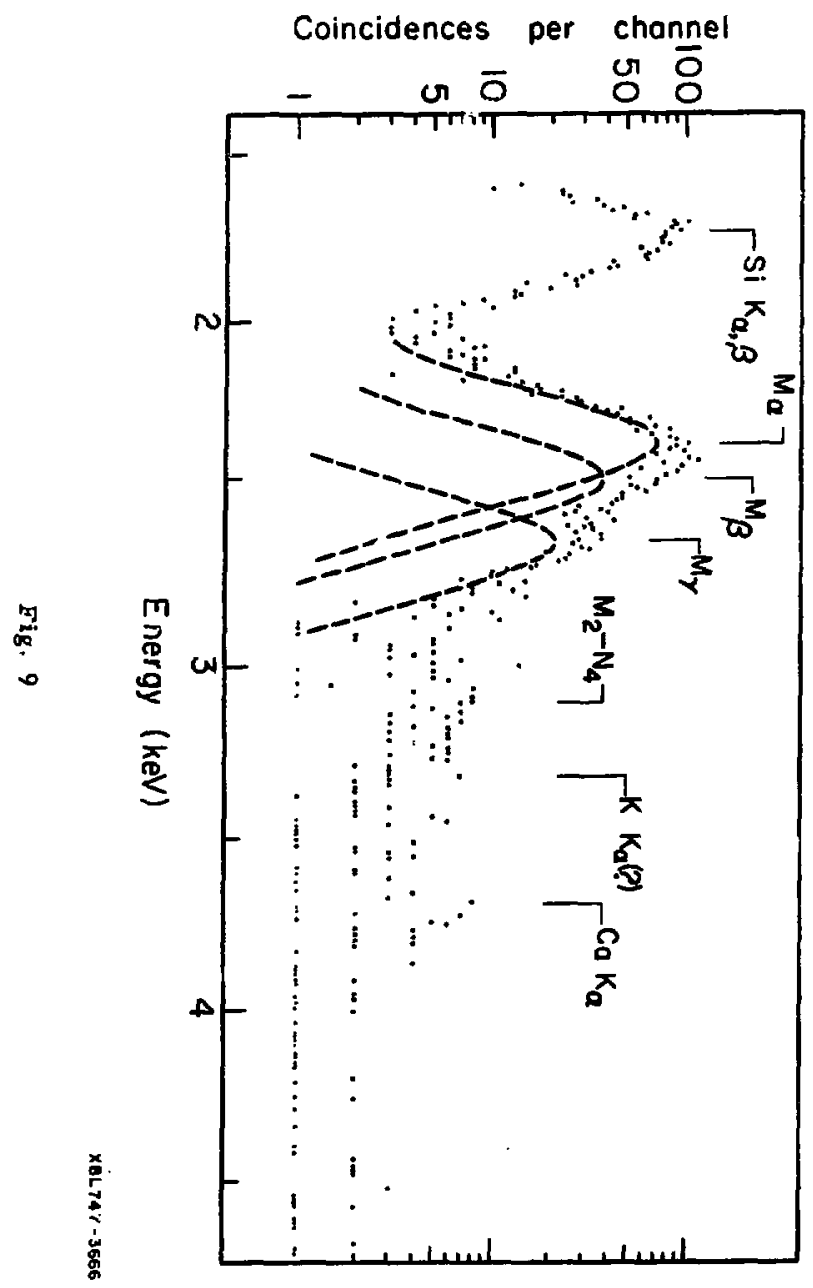




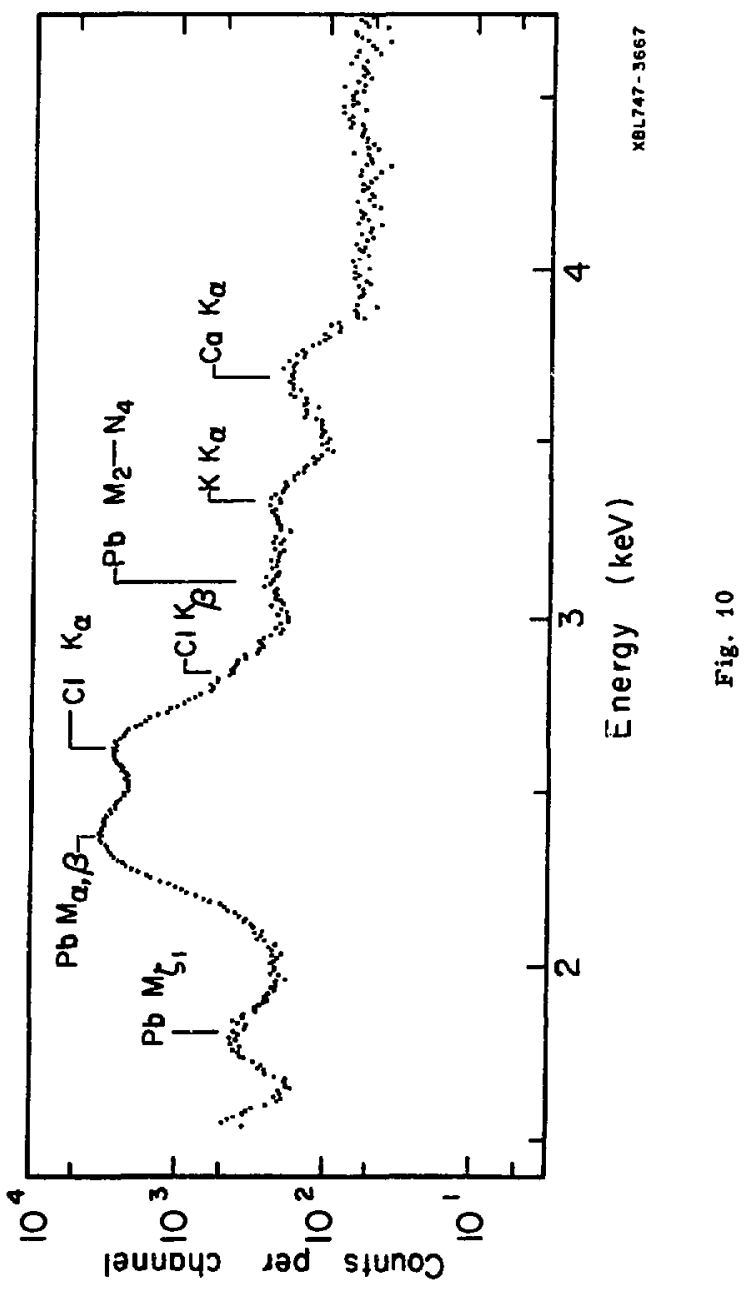




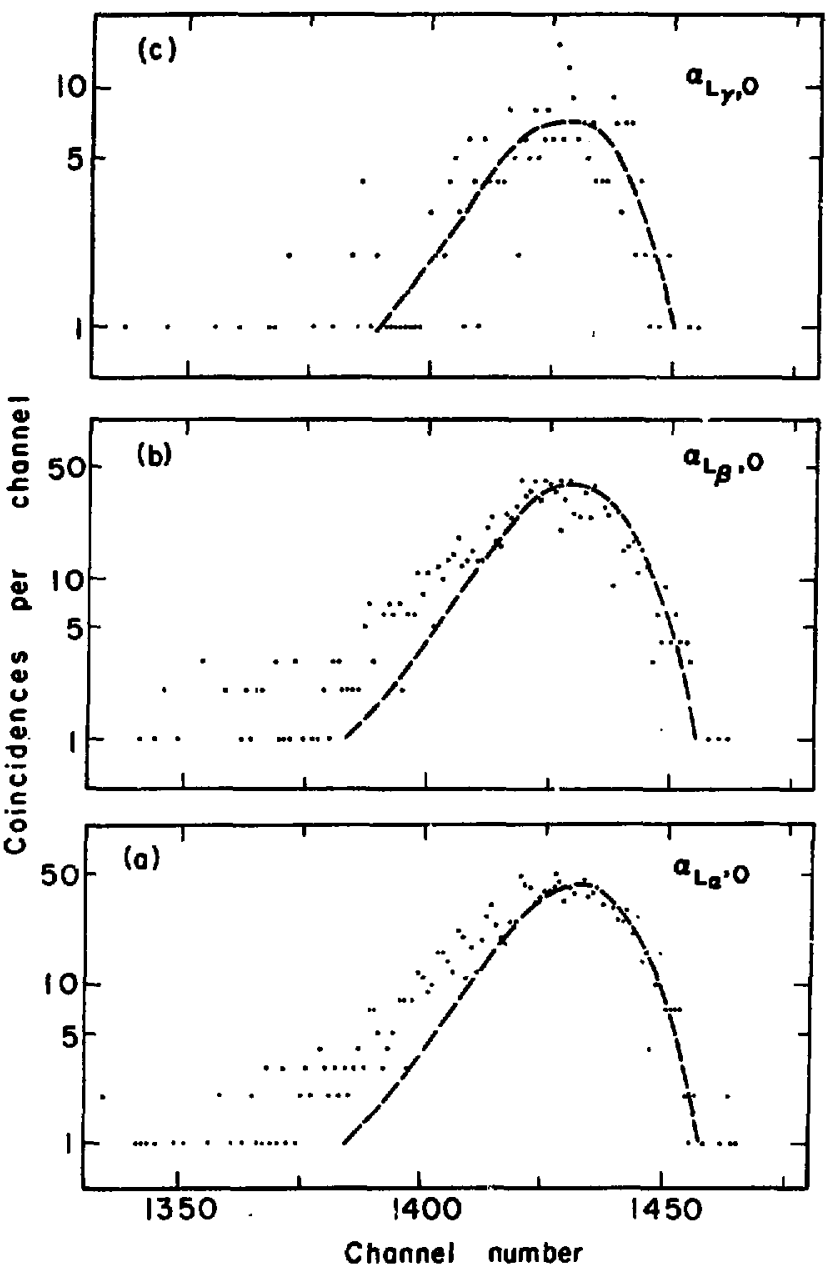

$x(1<145-3689$ 


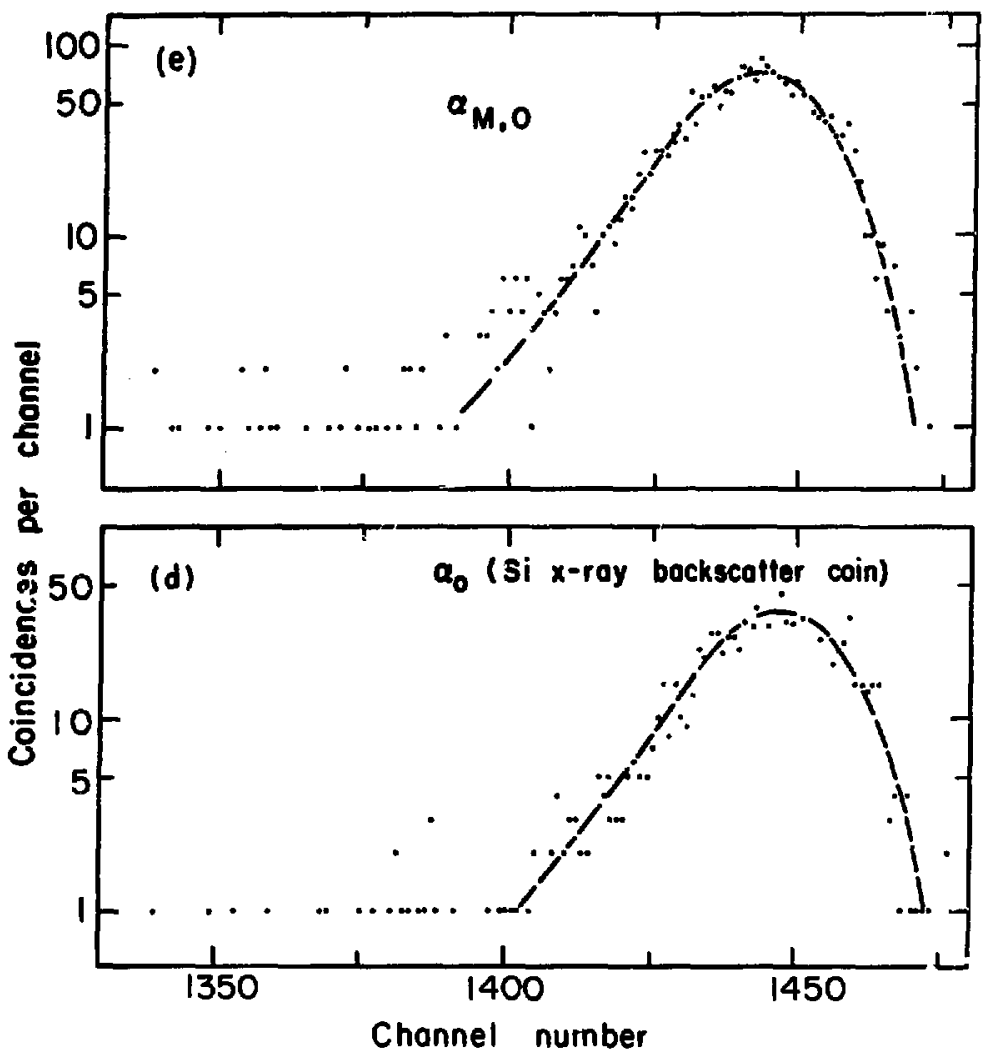

XBL747-366s

Fig. $11(d, e)$ 


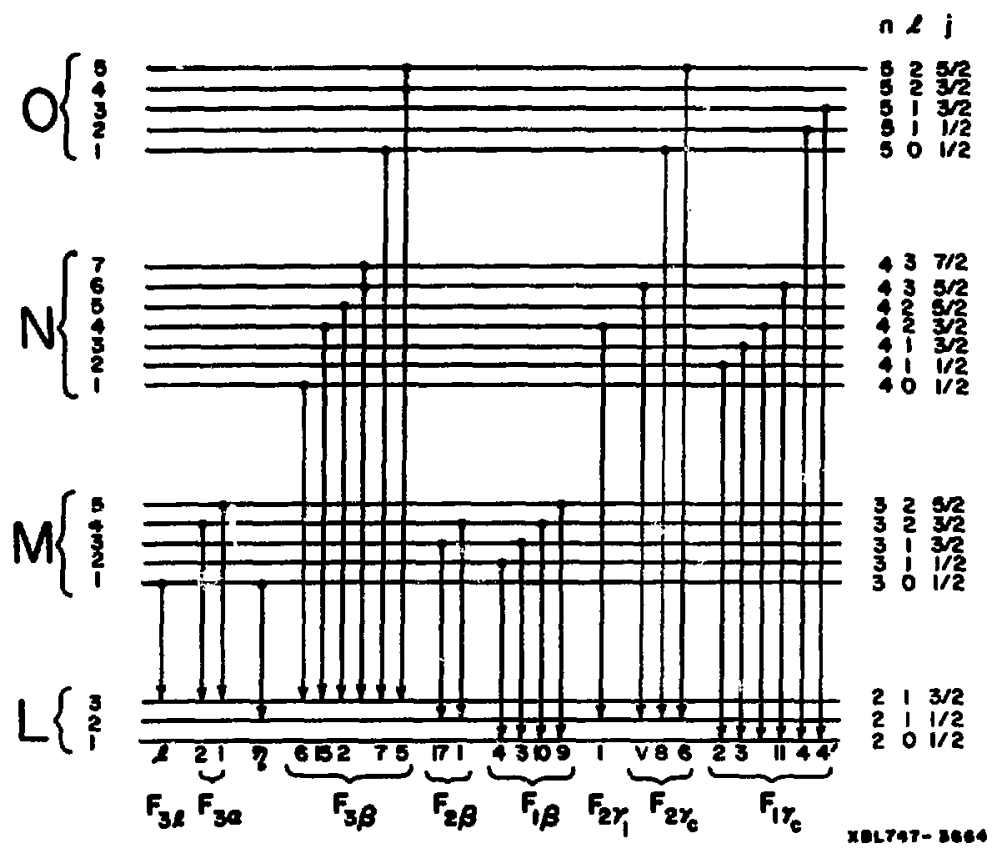

F1g. 12 
$-31-$

LBL-2978

$P_{{ }_{2}}$, and $P_{I_{3}}$ which are the probabilities per a particle of shaks-off in the $I_{1}, I_{2}$, and $I_{3}$ subshells respectively

$$
\begin{aligned}
& P_{I_{\alpha}}=\left[P_{L_{3}}+P_{L_{2}} f_{23}+P_{L_{1}}\left(f_{13}+f_{12} f_{23}\right)\right] w_{3} F_{3 \alpha} \\
& P_{I_{B}}=\left[P_{L_{3}}+P_{I_{2}} f_{23}+P_{I_{1}}\left(f_{13}+f_{12} f_{23}\right)\right] w_{3} F_{3 \beta} \\
& +\left(P_{L_{2}}+P_{L_{1}} F_{12}\right) w_{2} F_{2 B}+P_{L_{2}} w_{1} F_{1 B} \\
& P_{I_{Y}}=\left(P_{I_{2}}+P_{L_{1}} F_{12}\right) w_{2} F_{2 \gamma}+P_{I_{1}} w_{1} F_{1 \gamma} \\
& P_{I_{l}}=\left[\left(P_{I_{3}}+P_{I_{2}} f_{23}+P_{I_{1}}\left(f_{13}+f_{12} f_{23}\right)\right] w_{3} F_{3 l}\right.
\end{aligned}
$$

The experimental resolution of the $L$-rays was sufficient to resolve $I_{\gamma}$ into $I_{\gamma 1}$ and $I_{\gamma c}$ (Bee Pig. 12) and their probabilities can be expressed as

$$
\begin{aligned}
& P_{L_{Y 1}}=\left(P_{L_{1}} f_{12}+P_{L_{2}}\right) w_{2} F_{2 Y 1} \\
& P_{L_{Y c}}=\left(P_{L_{1}} f_{12}+P_{L_{2}}\right) w_{2} F_{2 Y C}+P_{L_{1}} \omega_{1} F_{1 Y C}
\end{aligned}
$$

also, $P_{L_{B 1,2}}$ and $P_{L_{B 4}}$ can be expressed as

$$
\begin{aligned}
\mathbf{P}_{\mathbf{L}_{B 1,2}} & =\left[\mathbf{P}_{L_{3}}+\mathbf{P}_{L_{2}} f_{23}+P_{L_{1}}\left(f_{13}+f_{12} f_{23}\right)\right] \omega_{3} F_{3 B 2} \\
& +\left(P_{I_{2}}+P_{I_{1}} f_{12}\right) \omega_{2} F_{2 B 1}
\end{aligned}
$$




$$
P_{L_{B 4}}=P_{L_{1}} W_{1} F_{1 B 4}
$$

where $f_{12}, t_{13}$ and $\varepsilon_{23}$ are the values of the coster Kronig yields and $w_{1}, w_{2}$ and $w_{3}$ are the values of the subshell fluorescense yields. Their values are: $\omega_{1}=0.08 \pm 0.02, \omega_{2}=0.363 \pm 0.015, \omega_{3}=0.315 \pm 0.013$, $f_{12}=0.15 \pm 0.04, f_{13}=0.57 \pm 0.03$ and $f_{23}=0.164 \pm 0.016 . F_{i j}$ represent the fraction of radiative transitions in the $L_{j}$ peak connected with filling a vacancy in the $L_{1}$ subshell. Thus, for example

$$
\begin{aligned}
F_{1 \beta} & =\frac{\sum \Gamma_{1 \beta}}{\Gamma_{1}} \\
& =\frac{\text { Intensity of } \Sigma \text { x-rays originating from } L_{1} \text { vacancies }}{\text { TotaI intensity of x-rays originating in } L_{1} \text { vacancies }} \\
& =\frac{\Gamma\left(L_{\beta 4}\right)+\Gamma\left(L_{\beta 3}\right)+\Gamma\left(L_{\rho 10}\right)+\Gamma\left(L_{\beta 9}\right)}{\Gamma_{1}}
\end{aligned}
$$

Two sets of radiative rateg were used. One was the set calculated by scofield ${ }^{43}$, and the other is an experimental set tabulated by Selem and Schultz ${ }^{44}$. Since Salem and schultz listed only the major transitions ( $>$ 904) their total values were normalized to Scofield's for the same transitions. From the I $x$-ray singles spectrum in the present work the ratio $F_{1 \beta} / F_{1 Y 2,3}$ agreed better with that determined fom Sales and Schultz's list than Scofield's. I therefore belleve the treatment using the former is the more accurate. Table I lists the values of $F_{1 j}$ used. 
The probabilities $\mathrm{P}_{\mathrm{L}_{1}}, \mathrm{P}_{\mathrm{L}_{2}}$ and $\mathrm{P}_{\mathrm{L}_{3}}$ were calculated (see Table II) by two different methods. In method I Eqs. (5) and (6), which are linearly independent, are easily solved sor $P_{L_{1}}$ and $P_{L_{2}}$. Then, from Eq. (1) $P_{I_{3}}$ is calculatr.d. In this method only the data obtained in the cotncidence run is used. The errors are calculated by assuming a maximum uncertainty of $10 \%$ in resolving $L_{Y}$ into $I_{\gamma}$ and $L_{\gamma c}$ and do not include any errors in the C.K. coefficients, $\omega$ or $F_{i j}$. The consistency of the calculation is checked by determining $P_{L_{8}}$ from Eq - (2) and the resulting value, $.99 \times 10^{-4}$ agreeg with the experimental value, $.97 \times 10^{-4}$. In method It the values of $\mathrm{P}_{\mathrm{L}_{\mathrm{B}, 2}}$ and $\mathrm{P}_{\mathrm{L}_{\mathrm{B} 4}}$ are obtained from the $x$-ray singles spectrim. Equation $(B)$ is solved for $P_{L_{1}}$, and then Eqs. (7) and (1) are solved for $P_{L_{2}}$ and $P_{I_{3}}$. With an assumption of 5. uncertainty in the determination of the ratio $P_{L_{\beta 4}} / P_{L_{\beta}}$. errors were calculated in the same way as for method $I$. With these calculated probabilities the abundance of $\mathrm{P}_{\mathrm{L}_{Y}}$ as determined from Eq $(3), .21 \times 10^{-4}$, agrees well with the experimental value $.22 \times 10^{-4}$. The results obtained in the two different methods also agree well with each other as shown in Table II, but method II gives more precise results and therefore the best values.

The total I shell tonization probability per $\alpha$ particle $P_{L}=$ $\mathrm{P}_{\mathrm{L}_{1}}+\mathrm{P}_{\mathrm{L}_{2}}+\mathrm{P}_{\mathrm{L}_{3}}$ is IIsted in Table II. Also listed, is the total photon yiald per $a$ particle, $P_{I_{x}}$, which was determined from the equation:

$$
P_{L_{X}}=P_{L_{1}}\left[w_{1}+f_{12} w_{2}+\left(E_{13}+f_{12} f_{23}\right) w_{3}\right]+P_{L_{2}}\left(w_{2}+E_{23} w_{3}\right)+P_{L_{3}}{ }^{\text {Ilt }}
$$


Table I. Normalized Salem and Schultz $F_{i j}$ values

1.

$3 \alpha$

$3 B$

$3 l$

$2 Y$

$2 \beta$

$1 Y$

$1 \beta$

$2 \Upsilon 1$

$2 \gamma \mathrm{c}$

IYc

184

2BI

382
$E_{i j}$

0.760

0.209

0.0336

0.201

0.774

0.274

0.693

0.172

0.0286

0.274

0.292

0.773

0.172 
The sensitivity of the calcuiated subshell shake-off probabjilties to the parameters, $w$ and $f$, was also considered. The vari,ution in ${ }_{13}$ and $f_{23}$ within the published errors result in the maximum changes of only 1 and 45 respectively in the ratlo $P_{I_{2}} / P_{L_{3}}$. However, the possible variations in the other paraneters result in a much more pronounced change as can be geen in Fig. 13(a-f). Variaticrs in more than one parameter at a +ime could result in even larger changes than injicated. It is evident that more precise experimental or theoretical values of the input parameters are desirabie.

\section{MX-Rays}

Figure 9 shows the photon radiation between $1.4 \mathrm{KeV}$ and 4.7 $\mathrm{KeV}$ in coincidence with 210 po a particles. $K$ and $\mathrm{si} x$-rays which were obtained by exciting $\mathrm{Kar}$ and $\mathrm{s} 1$ sources with ${ }^{55}$ Fe radiation, served as energy ard peak calibration standards. Silicon $k$ x-rays excited in the a detector during the coincidence measurement we:.a scactered into the x-ray detector and these also arved as an internal calibration. In the $x$-ray singles spectrum the $\alpha$ detector was masked by a nickel foil and Si x-rays were not observed.

The M x-ray coincidence spectrum was resolved into its three major components: $M_{\alpha}\left(M_{5}-N_{6,7}\right), M_{B}\left(M_{4}-N_{6}\right)$ and $H_{Y}\left(H_{3}-N_{5}\right)$. The 1 ine $\mathrm{M}_{3}-\mathrm{N}_{4}$ was also included in $\mathrm{M}_{\gamma^{*}}$. The abundances of the three components were determined as well as an upper limit on the number of counts registered in the $\mathrm{M}_{2}-\mathrm{N}_{4}$ peak. After correcting for the $x$-ray detector efficiency the abundances of $M_{\alpha}, M_{B}, M_{Y}$ and $M_{2}-N_{4}$ x-rays become 
Table II。 I Subshe11 Electron Shake-Off Probabilities

She11s

$\frac{\text { Probabilities } \times 10^{4}}{I^{*}} I I * *^{*}$

\begin{tabular}{lrr}
$P_{L_{1}}$ & $4.92 \pm .64$ & $5.11 \pm .60$ \\
$P_{L_{2}}$ & $.73 \pm .24$ & $.62 \pm .06$ \\
$P_{L_{3}}$ & $1.60 \pm .30$ & $1.50 \pm .19$ \\
$P_{L}$ & $7.25 \pm 1.18$ & $7.23 \pm .65$ \\
$P_{L_{x}}$ & $2.39 \pm .39$ & $2.37 \pm .21$ \\
\hline
\end{tabular}

- Method I with Salem and Schultz's $F_{i j}$

** Method II with Salen and Schultz's $F_{i j}$ 

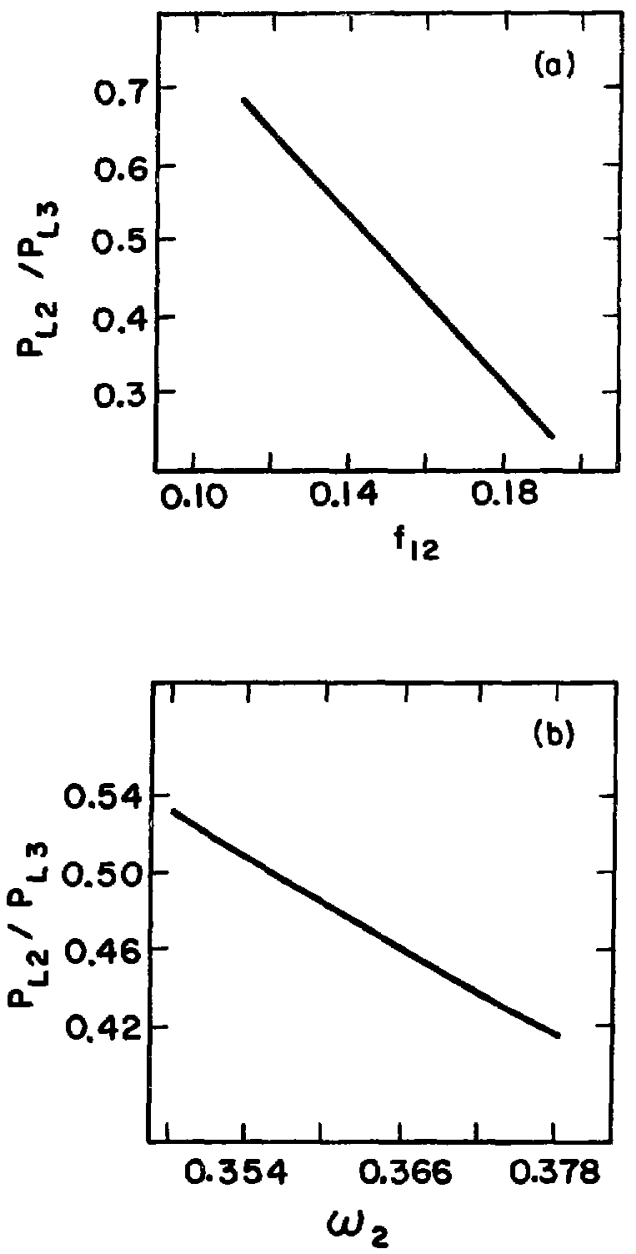

XBL 747-3662

Fig. $13(a, b)$ 

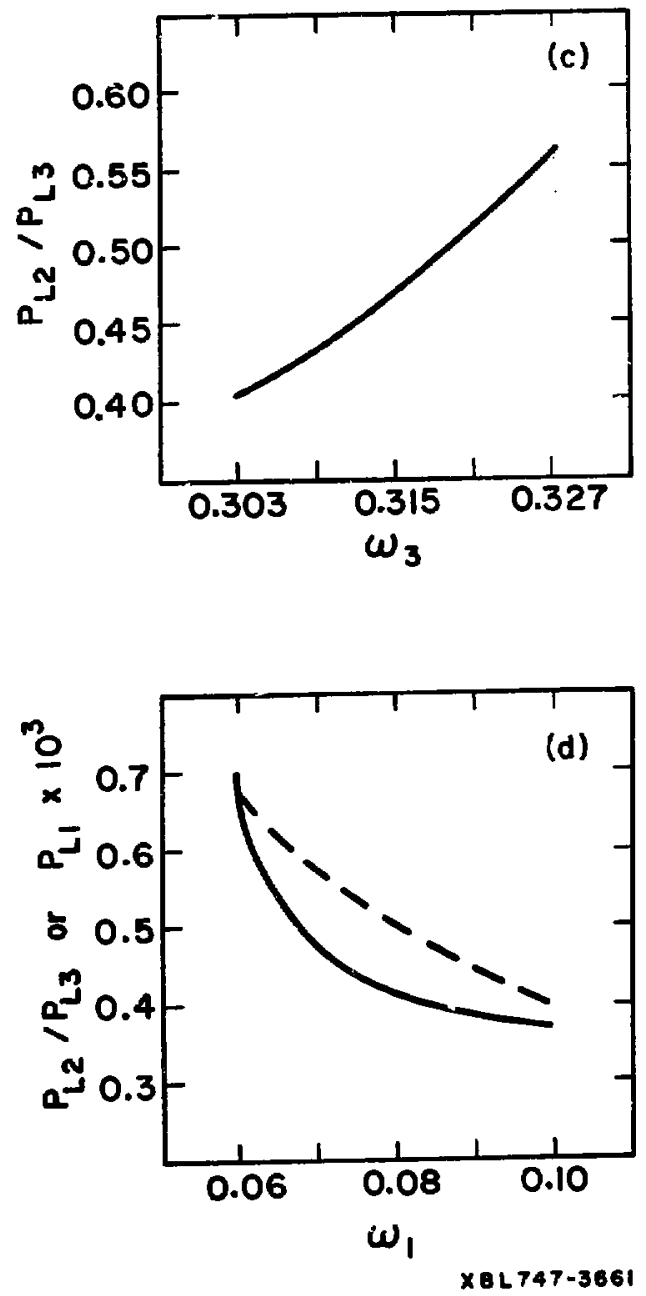

Fig. $13(c, d)$ 

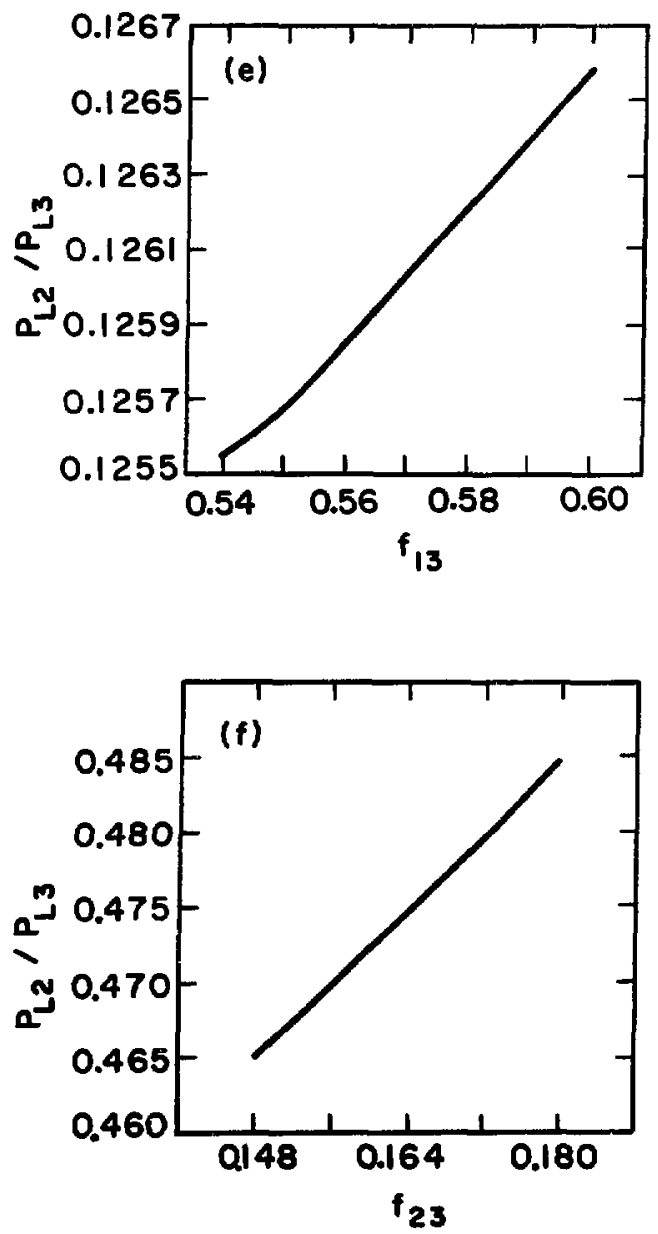

X日L747-3380

Fig. 13 te, 
$(2.9 \pm 0.6) \times 10^{-4},(1.5 \pm 0.3) \times 10^{-4},(0.78 \pm 3.16) \times 10^{-4}$, and

$<0.18 \times 10^{-4}$ reapectively. The ration of the line intensities are $H_{\alpha}: M_{B}: K_{\gamma}: M_{2}-N_{4}=100: 52: 27:<5$. These agree roughly with previous values 27 $100: 66.6: 33.3: 10$.

Figure 10 shows the correnponding $\boldsymbol{M}$ x-ray singles spectrum. Unfortunately, as was ertablished after the experimental work was conpleted, intense chlorine $\mathbf{K} \times$-ray peaks masked part of the lead $\mathbf{x - r a y}$ energy region. X-ray fluorescence analyses of the same kind of beryiliug foll as used for the ${ }^{210}$ po suurce backing plate, showed large anounts of the Cl x-ray peak. The chlorine poseibly arises from trichloro-

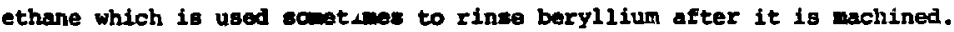
A low energy $x$-ray epectrum of ${ }^{241} \mathrm{n}$ deposited on the same typo of foil ahowed that $\mathrm{Cl} x$-rays were roughly proportional to the alphe activity of the source and indicated that lese than 1 of of the $M$ peak observed in the ${ }^{210} \mathrm{PO}$ coincidence expertent was due to $\mathrm{Cl} x-\mathrm{rays}$. The ${ }^{\mathrm{M}} \mathrm{ll}$ peak $\left(\mathrm{H}_{5}-\mathrm{H}_{3}\right)$, which was asked by $\mathrm{si} x$-rays in the coincidence experinent, is not affected in the singles wasurenent because of a $\mathrm{Ni}$ shield in front of the $\alpha$ detector. It abundance is $(0.23 \pm 0.05) \times 10^{-4}$ and the ratio $x_{\alpha}: x_{\zeta 1}$ is 100:0. This ratio agrees roughiy with that deduced froe the loulated ${ }^{45}$ radiative transition probabilities, $100: 3.5$ but is in conalderable diegreement with the ratio 27 100:55.

From the coincidence counting rate, the average $x-r a y$ detector afficlency in the if $x$-ray region and the a ingles counting rate, the photon yeild per a particlo, $P_{M}$, was calculated to be $(5.52 \pm 1.10) \times 10^{-4}$. 
With an average fluorescence yield, $\bar{w}_{M}=.03$, the total $M$ shell ionization probability per o particle is $P_{M}=(1.84 \pm .37) \times 10^{-2}$ excluding the uncertainty in the average fluorescence yield, The large error asgociated with the above results is mostly due to the large uncertainty (108) involved with the intensity of Np $M$-rays that were used in the efficiency calibration of the $x$-ray detector.

Equations similar to the one written for I $x$-rays above can be written for the $M x$-rays

$$
\begin{aligned}
& P_{M_{Y}}=P_{M_{3}^{*}}^{*} \omega_{3} F_{3 Y} \\
& P_{M_{B}}=\left(P_{M_{3}}^{*} f_{34}+P_{M_{4}^{*}}^{*}\right) \omega_{4} F_{4 B} \\
& P_{M_{\alpha}}=\left[\left(P_{M_{3}}^{*} E_{34}+P_{M_{4}}^{*}\right) f_{45}+P_{M_{3}}^{*} f_{35}+P_{H_{5}}^{*}\right] \omega_{5} F_{5 \alpha}
\end{aligned}
$$

where

$$
\begin{aligned}
& P_{M_{3}}^{\star}=P_{M_{3}}+P_{M_{2}} f_{23}+P_{M_{1}}\left(f_{13}+f_{12} f_{23}\right) \\
& P_{M_{4}}^{\star}=P_{M_{4}}+P_{M_{2}} f_{24}+P_{M_{1}}\left(f_{14}+f_{12} f_{24}\right) \\
& P_{M_{5}}^{\star}=P_{M_{5}}+P_{M_{2}} f_{25}+P_{M_{1}}\left(f_{15}+f_{12} f_{25}\right)
\end{aligned}
$$

but, the experimental data will not suffice to obtain unique results for the subshell ionization probabiltties. However, from this type of analysts it is possible to determine several limits on the ionization 
prababilities, e.g. $\mathrm{P}_{\mathrm{H}_{2}}=7-236, \mathrm{P}_{\mathrm{M}_{4}}<248, \mathrm{P}_{\mathrm{M}_{5}}<27 \mathrm{z} ; \mathrm{P}_{\mathrm{M}_{5}}+\mathrm{P}_{\mathrm{M}_{2}} \mathrm{f}_{25}<174 ;$ $P_{M_{4}}+P_{H_{2}} I_{24}<29 t_{1}$ and $P_{M_{1}}+P_{H_{3}}>470$ of the total. The input parameters used were taken from references 10 and 13 and an error of $10 \mathrm{~s}$ was assumed in their value and in the relative values of the intensities of the $x$-ray peaks.

\section{3. a spectra}

Figure 11 (a-e) presents the spectra of 8 days of experiment of ${ }^{210}$ Po a particles in coincidence with $x$-rays. The coincidences in Fig. 11 (a) are du: to a particles in coincidence with silicon $x \times$-rays as discussed in the $M \quad X-r a y$ section. This peak established the channel number that corresponded to ${ }^{210}$ po $\alpha_{0}$ particles and was later used as a standard peak shape in the coincldence run. The three spectra in Fig. $11(a-c)$ are due to $\alpha$ particles in coincidence with lead $I_{\alpha^{\prime}} L_{B}$ and $I_{Y}$ x-rays. The peaks are labeled $\alpha_{L_{c}, 0}, \alpha_{L_{\beta}, 0}, \alpha_{L_{\gamma}, 0}$ as suggested in the section on the $\mathrm{K}$ shell effect. Also drawn into each spectrum is the peak shape that would have been expected to be observed if the ejected olectrons carried-off zero kinetic energy and the initial vacancy distribution is as in Table II (aecond column). A stmilar plot for the $\alpha$ particles in coincidence with $M$ x-rays is presented in Fig. 11 (e). The following remarks can be made: (1) As mentioned earlier the number of accidental coincidences was insignificant and no accidental $\alpha$ peai is observed in Fig. $11(\mathrm{a}-\mathrm{c})$. (2) The peaks due to $\mathrm{L}_{\alpha}, \mathrm{L}_{B} \mathrm{z}_{\mathrm{a}} \mathrm{d} \mathrm{L}_{\gamma}$ art located $12.6 \pm 1.4,13.0 \pm 1.4$ and $17.6 \pm 2.1 \mathrm{KeV}$ lower than $\alpha_{0}$ in good agreament with their expected position (the binding energies of 
$L_{3}, L_{2}$ and $L_{1}$ electrons are 13.035, 15.200 and 15.861 KeV respectively). (3) The peak due to $\mathrm{M}$ x-rays is located $3.1 \pm 1.0 \mathrm{KeV}$ lower than $\alpha_{0}$ which is in good agreement with the $M$ binding energies of 2.5 to 3.9 KeV. (4) The peaks due to $L$ vacancies are broader than the one due to $M$ vacancies which in turn are only very slightly broader than the standard a feak. Also, every peak has a long tail on the lower energy side. 


\section{THEORY AND DISCLSSION}

The shake-off phencmenon accompanying $\alpha$ decay was treated by Migdal $^{l}$ as an example of adiabatic perturbation of the atomic cloud since the velocities of the $\alpha$ particles are much smaller than the velocities of the inner shell electrons. According to Migdal the perturbing potential is given by $v=-2\left[x^{2}+y^{2}+(z-v t)^{2}\right]-1 / 2$. Here the alpha particle moves with velocity $v$ along the positive $z$ axis. Levinger ${ }^{3}$ modified the perturbing potential by including the effect of the recoiling daughter nucleus (i.e. added to the above potential the term: $(z-2)\left[x^{2}+y^{2}+\left(z+v_{n} t\right)^{2}\right]^{-1 / 2}$ where $(z-2)$ is the charge of the daughter nucleus which recoils with velocity $v_{n}$ ) which reduced the ionization probability of a $\mathrm{K}$ shell electron by a factor of $\sim 25$. The latter probability is in total disagreement with experiment. However as was shown later ${ }^{19,23}$, this modification is incorrect. The ionization probabllities of inner shell electrons as calculated by the above two authors is given by agymptotic expansions. Migdal calculated only the first terms (dipole terms) of the expansions for the $\mathrm{K}, \mathrm{L}$ and $\mathrm{M}$ electrons (see Ref. 1, Eq. (21)). In addition to his modification of the perturbing potential Levinger calculated also the gecond terms (quadrupole terms) of the expansions. He neglected the recoil effect in the quadrupole term since its contribution to that term was very small; hense recalculated the shake-off probabilities for $\mathrm{K}$ and $\mathrm{L}$ electrons only (see Ref. 3: Table IV corrected as noted by author). When the recoll colntribution to the ionization probabilities is factored out, Levinger's results of the calculation of the dipole 
term are identical to Migdal's.

In the above calculations the bound electrons and the electrons ejected into the continuum are described by non-relativistic hydrogenic type wave functions. A more realistic set of wave functions would be of the self consistent type. In the following paragraphs, the details of Migalal's treatment with the latter type of wave functions of the K shell Ionization accompanying $\alpha$ decay are described.:

According to Migdal the probability of ionizing one of the is electrons is given by:

$$
\begin{aligned}
d v_{1 s} & =\frac{8 v^{2}}{3\left(E_{k}-B\right)}|<k, \ell=1| \frac{1}{r^{2}}|l s>|^{2} d E_{k} \\
& + \text { much smaller terms }
\end{aligned}
$$

where $v$ is the velocity of the $\alpha$ particle, $B$ is the binding energy of a Is electron and $E_{k}$ is kinetic energy carried off by the ionized $1 s$ electron. The matrix element can be readily calculated with hydrogenic wave functions and the probability equation becomes:

$$
d P_{1 s}=\frac{2^{11} v^{2}}{3 \cdot z^{6}} \frac{e^{-\frac{4 z}{k} A r c t a n} k / z}{\left(1+\frac{k^{2}}{z^{2}}\right)^{5}\left(1-e^{-2 \pi z / k}\right)^{d E_{k}}}
$$

where $\mathrm{z}$ is the charge of the daughter nucleus and $\mathrm{k}=\sqrt{2 \mathrm{E}_{\mathrm{k}}}$. One gets the total ionization probability by numerical integration.

The hydrogenic type wave functions used in Eg. (13) were replaced by Hartree-Fock-slater wave functions (H-F-S). For the bound $1 \mathrm{~B}$ electrons use was made of H-F-S radial wave functions that are already tabulated. 46 The continuum-electron radial wave functions, $P_{k l}$ 
(described by the wave vector $k$ and the angular momertim $\ell$ ), were determined by numerically solving the radial equation

$$
\left(\frac{d^{2}}{d r^{2}}-\frac{\ell(\ell+1)}{r^{2}}-2\left[E_{k}-V(r)\right]\right) \quad P_{k \ell}(r)=0
$$

The potential $V(r)$ was the tabulated ${ }^{46}$ H-F-s central potential that wa! developed in the H-F-S solution for the bound electrons. The Numerov 47 integration method was applied until the solution became asymptotic. The two points at small $r$ required to generate the solutions were taken to be hydrogenic. The asymptotic solution is known to be 48

$$
p_{k \ell}(x) \approx\left(\frac{2}{\pi k}\right)^{1 / 2} \cos \left[k x+k^{-1} \ln (2 k x)-\frac{1}{2} \pi(\ell+1)-\delta_{\ell}\right]
$$

where $\delta_{\ell}=\arg \Gamma\left(\ell+1+i \frac{z}{k}\right)$ is the complex phase of the $\Gamma$-function. Using the derivative of $\mathrm{Eq} .(16)$ one can write

$$
p_{k \ell}^{2}(r)+\frac{p_{k \ell}^{\prime 2}(r)}{\left(k+\frac{1}{k r}\right)^{2}}=\frac{2}{\pi k}
$$

Equation (17) is independent of $x$ for large $x$. Thus, the numerical solution for the continuum wave function can be normalized by requiring Eq. (17) to hold for larce $r$. With these solutions and the tabulated 46 1. wave functions the matrix elements in $\mathrm{Eq}$. (13) were calculated and the probability vg. energy relation was obtained. The total probubility was obtained by mumerical integration.

Table III 1igts the values of the matrix elements calcualted for ${ }^{210}$ pu as a function of the kinetic energy carried off by the 
ionized is electron. The energy distribution calculated fram Eq. (13) with H-F-S type wave functions are almost identical with those calculated with the hydrogenic type (see Eq. (14)).

Using the calculations of shake-off probability as a function of electron energy and the experimental average peak shape in the ${ }^{210}{ }_{\text {PO }}$ a singles spectrum the shape of the a spectrum associated with the shake-off of $K$ electrons which would be expected from Migdal's theory was determined. The theoretical shape was normalized to the same peak height as the experimental curve and is shown as a dashed line in Fig. 7. The $\alpha$ singles spectrum had a sall perturbation about 300 KeV below the peak due to instrumental effects and this is reflected in both the calculations and the coincidence spectrum. As seen in Fig. 7, there is a definite discrepancy between the experimental and theoretical curves. The probability of electron shake-off decreases more rapidly than the theoretical prediction as the electron energy increases (i.e., as the $\alpha$ particle energy decreases). Ovechkin and Tsenter ${ }^{23}$ observed the same effect in comparing electron energy measurements with Migdal's calculations, but the authors felt their experimental work was not oufficiently precise to indicate a definite decrepancy.

The total probability of electron (ree Table IV) shake-off from the $K$ shell was calcualted from Egg. (13) and (14). In Eq. (14), 2 the charge of the daughter nucleus was replaced by the effective charge $\mathrm{z}^{*}, \mathrm{z}^{*}$ (uranium) $=91.26$ and $\mathrm{z}^{*}($ lead $)=81.27$. Here, $\mathrm{v}(\alpha$ particle $)$ (1. electron) is 0.0817 for uraniun and 0.0899 for lead. 
Table III. Matrix Element (Eq. 13) as a Function of Electron Energy

\begin{tabular}{|c|c|c|c|c|c|c|c|c|}
\hline \multirow[t]{2}{*}{ Energy" } & \multicolumn{2}{|c|}{$\leq \geq \times 10^{-1}$} & \multirow{2}{*}{ Znergy } & \multicolumn{2}{|c|}{$\geq \times 10^{-3}$} & \multirow[t]{2}{*}{ Energy } & \multicolumn{2}{|c|}{$\leq 2 \times 10^{-1}$} \\
\hline & $a$ & b & & a & b & & a & $\mathbf{b}$ \\
\hline 1. & 4.2972 & 4.8347 & 400 & 4.4003 & 4.9254 & 1700. & 4.6233 & 5.1367 \\
\hline 10. & 4.3004 & $4.8 * 15$ & 500. & 4.4226 & 4.9454 & 1800. & 4.6346 & 5.1493 \\
\hline 20. & $4.30=8$ & 4.8406 & 600. & $4.443 E$ & 4.9617 & 1900. & 4.6464 & 5.1615 \\
\hline 30. & 4.3056 & 4.8435 & $7 n n$. & 4.4641 & 4.9833 & 2000 & 4.6577 & 5.1733 \\
\hline 40. & 4.3089 & 4.8455 & $8 \% 0$. & 4.4834 & 5.0013 & $21 n 0$. & 4.6685 & 5.1846 \\
\hline 50. & 4.3114 & 4.8473 & 900. & 4.5018 & 5.0187 & 2200 & 4.6790 & 5.1956 \\
\hline 60. & 4.3140 & 4.8491 & 1000 & 4.5194 & 5.0354 & 2300 & 4.6889 & 5.2063 \\
\hline 70. & 4.3169 & 4.8511 & 1100 & 4.5361 & 5,0514 & 2400 & 4.6986 & 5.2166 \\
\hline 80. & 4.3199 & 4.8533 & 1200 & 4.5521 & 5.0669 & 2500 & 4.7078 & 5.2266 \\
\hline 90. & 4.3228 & 4.8556 & 1300 & 4.5675 & 5.0819 & 2600 & 4.7166 & 5.2363 \\
\hline 100 & 4.3256 & 4.8599 & 1400. & 4.5821 & 5.0963 & 2700 & 4.7251 & 5.2457 \\
\hline 200. & 4.3529 & 4.8823 & 1500. & 4.5961 & 5.1103 & 2800 & 4.7333 & 5.2548 \\
\hline 300. & 4.3770 & 4.9046 & 1600. & 4.6095 & 5.1237 & 2900. & 4.7412 & 5.2636 \\
\hline
\end{tabular}




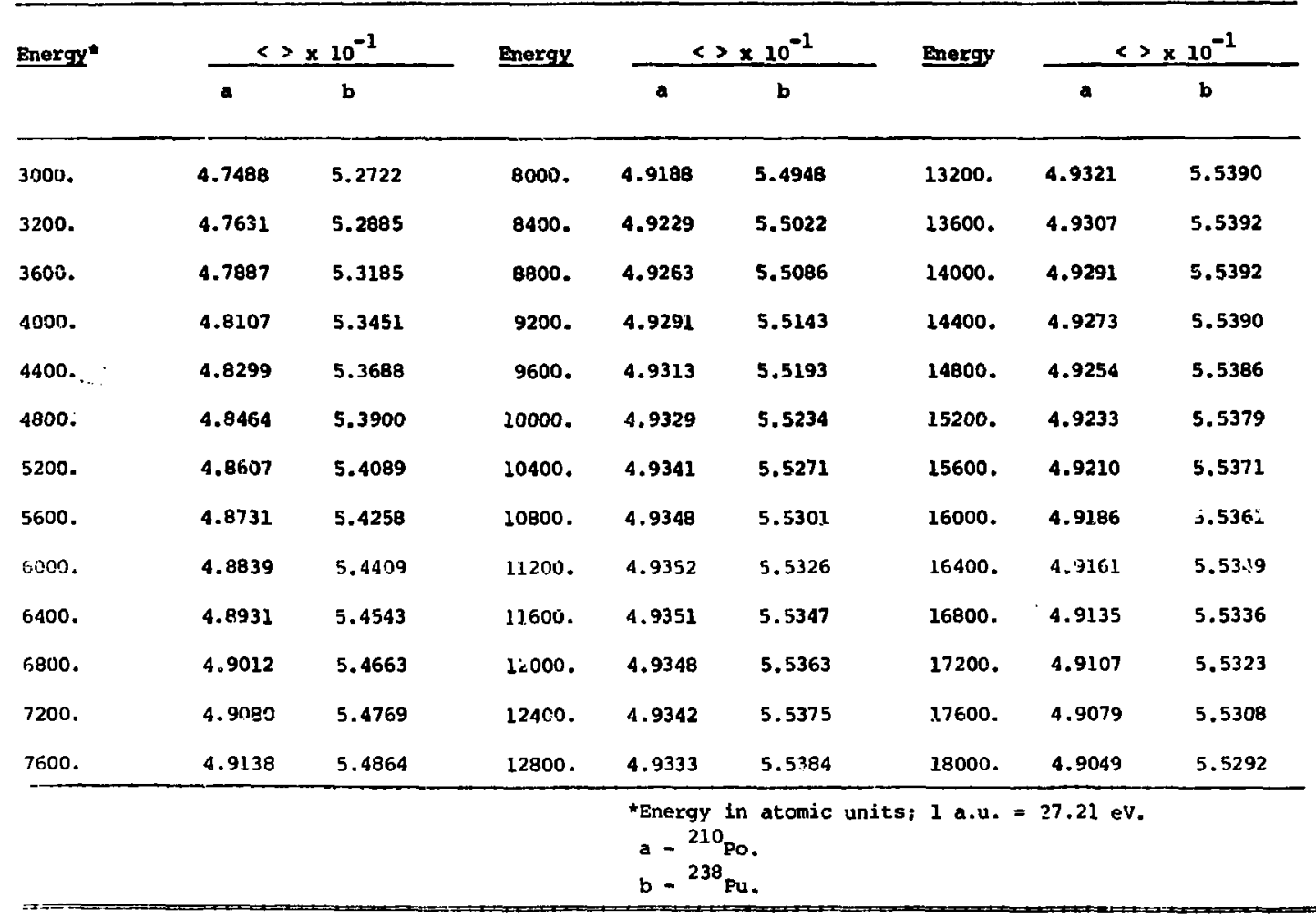


Table IV. Probability of Electron Shake-off From the $\mathrm{K}$ Shell

Isotorye Ref. Experiment Stated Error Theory (Hydrogenic) Theory (H-F-S) Hansen 19

\begin{tabular}{|c|c|c|c|c|c|c|}
\hline $210 \mathrm{Po}$ & 24 & $1.5 \times 10^{-6}$ & \pm 336 & - & & \\
\hline & 25 & 2.0 & \pm 168 & & & \\
\hline & 25 & 1.6 & \pm 318 & & & \\
\hline & 20 & 1.5 & \pm 278 & & & \\
\hline & $\begin{array}{l}\text { This } \\
\text { work }\end{array}$ & 1.65 & \pm 10 b & $2.67 \times 10^{-6}$ & $2.87 \times 10^{-6}$ & $2.02 \times 10^{-6}$ \\
\hline${ }^{238} \mathrm{Pu}$ & 15 & 0.51 & \pm 508 & & & \\
\hline & $\begin{array}{l}\text { This } \\
\text { work }\end{array}$ & 0.75 & \pm 128 & $1.75 \times 10^{-6}$ & $1.66 \times 10^{-6}$ & \\
\hline
\end{tabular}


Recently, Hansen ${ }^{19}$ in a different type of theoretical treatment calculated the shake-off probabilities of $K, L$ and $M$ electrons. In his treatment, the above probabilities were described as special zeroimpact-parameter trajectories in the generalized impact-parameter formulation of a binary encounter approximation. Hansen had taken into account two additional effects not accounted for in Migdal's theory: relativistic effects and the variation of the kinetic energy of the $\alpha$ particle in the vicinity of the nucleus. His result, $2.02 \times 10^{-6}$ is somewhat closer in agreement with the experimental result than any of the theoretical values. Unfortunately the shake-off probability as a function of electron energy was not calculated by Hansen. Table IV summarized the experimental results and the theoretical results on the shake-off effect in the $\mathrm{K}$ shell accompanying $\alpha$ decay.

In Table $V$ the experimental work on $L$ and $M$ electron shake-off up to date is sumuarized and compared with theoretical predictions. The following values of the erfective charge were used: $z^{\star}(2 \mathrm{~s})=77.34$, $z^{*}(2 p)=76.23, z^{*}(3 s)=69.28, Z^{*}(3 p)=67.33$ and $z^{*}(3 d)=64.81$. Here the values of alpha particle velocity over electron velocities are $0.189,0.192,0.316,0.325$ and 0.338 for $2 s, 2 p, 3 s, 3 p$ and $3 d$ electrons respectively.

The I subshells ionization probabilities as listed by Migdal and Levinger are all smaller than the probabilities calculated from the experiment and the theoretical series expansion converges rather slowly. These suggest the need to calculate additional terms in the expansion. Also, a more realistic set of wave function, relativistic 
Table V. Probability of Electron Shake-off From the $L$ and $M$ Shells

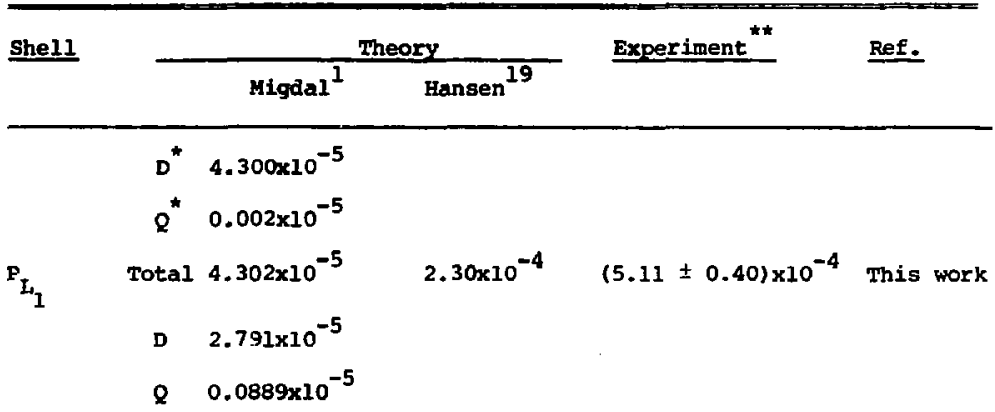

$P_{I_{2}}$ Total $3.680 \times 10^{-5} \quad 0.76 \times 10^{-4} \quad(0.62 \pm 0.06) \times 10^{-4}$ This work

D $\quad 5.582 \times 10^{-5}$

Q $2.525 \times 10^{-5}$

\begin{tabular}{lllll}
$P_{I_{3}}$ & Total $8.107 \times 10^{-5}$ & $2.86 \times 10^{-4}$ & $(1.50 \pm 0.19) \times 10^{-4}$ & This work \\
$P_{L}$ & $1.61 \times 10^{-4}$ & $5.9 \times 10^{-4}$ & $(7.23 \pm 0.65) \times 10^{-4}$ & This work \\
$P_{L_{X}}$ & $0.54 \times 10^{-4}$ & $1.83 \times 10^{-4}$ & $(2.2 \pm 0.5) \times 10^{-4}$ & 3 \\
& & $(2.93 \pm 0.43) \times 10^{-4}$ & 4 \\
& & $(2.79 \pm 0.42) \times 10^{-4}$ & 5 \\
$P_{M}$ & & $4 \times 10^{-4}$ & 2 \\
$P_{M}$ & $1.67 \times 10^{-3+}$ & $1.90 \times 10^{-2}$ & $(1.84 \pm 0.37) \times 10^{-2}$ & This work \\
& $5.01 \times 10^{-5+}$ & $5.7 \times 10^{-4}$ & $(5.52 \pm 1.10) \times 10^{-4}$ & This work \\
& & $1.5 \times 10^{-3}$ & $2.37 \pm 0.21) \times 10^{-4}$ & This work \\
& & & $0.91 \times 10^{-3}$ & 5 \\
\hline
\end{tabular}

^ $D=$ Dipole term, $Q=$ Quadrupole term

* The errors in the present work do not include uncertainties in the values of $\omega, f$ and $F_{i j}$.

+ Dipole term only. 
Hartree-Fock wave functions for example, should be used in the calculations rather than hydrogenic type wave functions, slailar remarks can be made with regard to $\mathrm{A}$ shell shake-off calculations.

Hansen"s calculation for the $t$ and $y$ ahells are in far better agreement with experimental result than Migdal's theory. His photon yields agree well with experiwent. However, the agreement is not good for the Individual I subshell ionization probabilities. However, this is not reflected in the photon yield since the latter is not very sensitive to the initial subshell vacancy alstribution. It will be interesting to compare the differential shape of the $\alpha$ spectrur with the differential shape that Hansen's treatnent will predict and is yet to be calculated.

In addition to comparing experimental shake-off probabilities with theoretical predictions, the former could be compared with experimental Lonization of lead by 5.3 Mev $\alpha$ particle bombardment. Unfortunately measurements at this energy have not been reported. Available 49 are $\mathrm{Pb} \mathrm{L}$ subshell ionization cross-section ratios $\vee s$ proton bonbarding energy from 0.5 to $4 \mathrm{MeV}$. Also reported ${ }^{50}$ are cross-sections for $I$ subshell ionization in Au by collision of protons $(0.25-5.2 \mathrm{MeV})$ and $\alpha$ particles $(1-12 \mathrm{meV})$. The latter measurements show that for energies greater than $21.4 \mathrm{HeV} /$ nucleon the $I$ subshell ionization crossscetion ratios for proton bombardment are very similar to the ratios for $\alpha$ particle bombardment. Therefore good estimate of lead ionization cross-section 
$-54-$

LBL-2978

ratios by $5.3 \mathrm{MeV}(1.32 \mathrm{MeV} /$ nucleon) a particles was obtained from reference 49. These ares $\sigma_{L_{2}} / \sigma_{L_{1}} \approx 3.2$ and $\sigma_{L_{3}} / \sigma_{L_{2}} \approx 4.0$. The joniration probability ratios due to shake-off effect are: $P_{L_{2}} / P_{I_{2}}=0.12$ and $\mathrm{g}_{\mathrm{L}_{3}} / \mathrm{P}_{\mathrm{L}_{2}}=2.4$. Thus, $\sigma_{\mathrm{L}_{3}} \sigma_{\mathrm{L}_{2}}>\sigma_{\mathrm{L}_{1}}$ while $\mathrm{P}_{\mathrm{L}_{1}}>\mathrm{P}_{\mathrm{L}_{2}}>\mathrm{P}_{\mathrm{L}_{2}}$. 


\section{v. SUMMARY AND CONCLUSION}

Most of the new information presented in this paper concerns the direct observation of that part of the alpha spectrum connected with the electron shake-off effect in the $K, I$ and $M$ shells. These

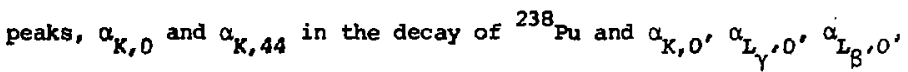
$\alpha_{L_{Y}, 0}$ and $\alpha_{M, 0}$ in the decay of ${ }^{210}$ Po, were experimentally observed for the first time. As conservation of energy sequired the energy differences between $\alpha_{0}$ in ${ }^{210}$ Po and ${ }^{238} \mathrm{Pu}$ and $\alpha_{44}$ in ${ }^{238} \mathrm{Pu}$, and their corresponding $\alpha$ shake-off peaks were equal to the binding energies of the ionized electrons. The shape of the $\alpha$ spectra indicated that part of the l.atter were ejected with kinetic energy greater than zero.

It is clear that Migdal's theory still prexicts ionization probabilities of $\mathrm{K}$ electrons approximately twice as high as observed experimentally. The use of $\mathrm{H}-\mathrm{F}-\mathrm{S}$ type wave functions has little effect on the total ionization probabilities. Also, the energy distributions calculated with H-F-S type wave functions are almost identical with those calculated with the hydrogenic type. The theoretical energy distribution of the ejected electrons does not fall as rapidly with increasing energy as the experimental one.

It is possible the discrepancies mentioned above could be reduced by using relativistic Hartree-Fo ck wave functions. These wave functions ghould be made very accurate at small distances since this is the region where most of the strength of the matrix elements lies. An experimental study of ${ }^{148} \mathrm{Gd}$ similar to the ones presented 
In this paper should indicate if Migdal's theory gives the proper dependence on both charge and alpha particle energy.

For better comparison between Migdal's theory and the shakeoff phenomena in the $L$ and $M$ she?ls it is necessary to calculate additional terms in the asymptotic expansion.

Hansen's new theoretical treatment predicts ionization probabilities in closer agreement with experiment than Migdal's. However, discrepancies still exist. Also energy distributions for the ejected electrons were not calculated. It is clear that more experimental. investigations of $L$ and $M$ shell electrons is needed. The analysis of these experiments will be more complicated due to the presence of $L$ and $M x$-rays that originate in the internal conversion process. Measurements of the abundance of $N$ shell effect, which should be substantially larger than that in the $M$ shell, could indicate what would be the "best" alpha peak shape or resolution which present-day high-resolution $\alpha$ spectrometers could obtain. 


\section{RFFERENCES}

1. A. Migdal, J. Phys. (USSR) 4, 449 (1941).

2. E. L. Feinberg, J. Phys, (USSR) 4, 423 (1941).

3. J. S. Ievinger, Phys. Rev. 90, 11 (1953); J. Phys, Rad. 16, 556 (1955).

4. T. A. Carlson, C. H. Nestor, Jr., T. C. Tuoker, and F. B. Malik, Phys. Rev. 169, 27 (1968).

5. A. J. Nord, itucl. Phys. Al92, 305 (1972).

6. J. Law and J. I. Campbell, Nucl. Phys. Al85, 529 (1971); Nucl. Phys. A187, 525 (1972); Nucl. Phys. A199, 481 (1973).

7. T. Mukoyama, Y. Isozumi, T. Kitahara, and S. Shimizu, Phys. Rev. C . $1308(1973)$.

8. R. I. Intemann, Mucl. Phys. A219, 20 (1974).

9. T. Mukoyama, T. Kitahara, and S. Shimizu, Phys. Rev. C 9, 2307 (1974).

10. T. Mukoyama, and S. Shimizu, Phys. Rev. C g., 2300 (1974).

11. C. พ. E. Van Ejjk and T. ค. Kooy, Phys. Letters 46B, 351 (1973).

12. J. L. Campbell and J. Law, Can. J. Phys. SO, 2451 (1972).

13. Y. Isozumi and S. Shimizu, Fhys. Rev. C 4, 522 (1971).

14. E. der Mateosian, Phys. Rev. A $\underline{3}, 573$ (1971).

15. H. J. Nagy, G. Schupp, and R. R. Hurst, Phys, Rav. C 6, 607 (1972).

16. A. Bond, O.P. Gupta, and A. Zide, Phys. Rev. C 9, 1529 (1974).

17. C. W. E. Van Eifk, R. W. Kooy, and M. J. C. Visscher, Phys. Rev. C 9, 2074 (1974).

18. F. T. Porter, M. S. Freedmann, and F. Wagner,Jx., Phys, Rev. C 3 , 2246 (1971). 
19. J. S. Hansen, Phys, Rev, A 9, 40 (1974).

20. M. A. Grace, R. A. Allen, D. Mest, and H. Halban, Proc. Phys. Soc. (London) $\mathbf{1 6 4}, 493$ (1951).

21. H. C. Barber and R. H. Helm, Phys, Rev, 86, 275 (1952).

22. H. Rlou, J. Phys, Rad. 13, 487 (1952).

23. V. V. Ovechkin and E. M. Tsenter, Soviet J. At. Energy, English Transl. 2 , 344 (1957).

24. I. Curie and F. Joliot, J. Phys. Rad, 7, 20 (1931).

25. M. Riou, J. Phys. Rad. :3, 487 (1952).

26. W. Rubinson and w. Berngtrin, Phys. Rev. 86, 545 (1952).

27. . Rubinson, Phys. Rev. 130, 2011 (1963).

28. C. M. Iederer, private comunication.

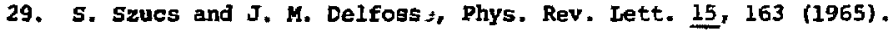

30. K. C. K, Gïnter, F. Asaro, and A. C. Helmholz, Phys. Rev. Lett: 16, 362 (1966)

31. G. I. Cano and R. W. Dressel, Phys. Rev. Al?5, 1883 (1965).

32. N. Perrin and พ. de wieclawick, C. R. Acad. Sc. 262, 511 (1966);

C. R. Acad. Sc. 266, 577 (1968); C. R. Acad. Sc. 268, 1268 (1969).

33. J. Meyer, J. M. Paulus, and J. Ch. Abbe, Radiochimica Acta 17, 76 (1972).

34. G. C. Nestor, B. G. Sounders, and S. T. Salem, atomic data I., 337 (1970).

35. J. S, Hansen, J. C, McGeorge, D. Nix, W.D. Schmidt - Ott, I. Unus and R. W. Fink, Nucl. Ingtr. and Meth. 106, 365 (1973).

36. J. Legrand, Nucl. Instr, and Meth, 112, 229 (1973). 
37. J. I Campball and I. A. Mckelles, Mucl. Instr. and Meth. 98, 433 (1972).

38. D. A. Landis, C. F. Jones, B. V. Jarrett, A. Jue, and s. D. Wright, LDLD-540, June 1972 .

39. Unpublished

40. Nuclear Data Sheets B5/6, 648 (1971).

41. R. S. Hager and E. C. Seltzer, Nuclear Data Tables A4, 1 (1968).

42. W. Bambyneix, B. Crasemann, R. W. Fink, H. U. Freund, H. Mark,

C. D. Swift, R. B. Price and P. Venugopala Rao, Rev. Mad. Fhys. 44, 716 (1972).

43. J. H. Scofield, Phys. Rev. 179, 9 (1969).

44. S. I. Salem and C. w. Schultz, Atomic Data 3, 215 (1971).

45. C. P. Bhalla, J. Phys. B $\underline{3}, 916$ (1970).

46. F. Herman and S. Skillman, Atomic Structure Calculations, PrriticeHall, Inc. (1963).

47. J. M. Blatt, J. Comp. Phyg. 1, 382 (1967).

48. H. Bethe and E. E. Salpeter, guantum Mechanics of one and Two Electron Atomg, Academic, New York (1957):

49. D. H. Madigon, A. B. Baskin, C. E. Busch, and S. M. Shaforth, Phys. Rev. A 9,675 (1974).

50. S. Datz, J. L. Duggan, L. C. Feldman, E. Laegsgaarả, and J. U. Anderson, Phys. Rev. A 9 , 192 (1974). 


\section{FIGURE CAPTIONS}

Fig. 1 Block dlagran of électronics used for $\alpha-k x-r a y$ coincidence meaturements.

Fig. $2{ }^{210_{\text {Po }}}$ photon radiation between $20 \mathrm{KeV}$ and $150 \mathrm{KeV}$.

FIg. $3238_{\mathrm{Pu}}$ photon radiation between $35 \mathrm{KeV}$ and $180 \mathrm{KeV}$.

Fig. 4 Block diagram of electronics used for $\alpha-L$ and $A x$-ray coincidence measurements.

Fig. $5{ }^{238}$ Pu $\alpha$ spectrum in coincidence with uranium $k_{B} x$-rays.

Fig. 6 Partial decay scheme of ${ }^{238} \mathrm{Pu}$.

Fig. $7210_{\text {Po }} \alpha$ spectrum in colncidence with lead $\mathrm{K}_{\alpha}$ x-rays. -theoretical shape normalized to peak height.

Fig. 8 Lead $L$ x-rays $\left(8.37 \mathrm{ev} /\right.$ channel) in coincicince with ${ }^{210}$ Po $\alpha$ particles.

Fig. 9 Lead $M$ x-rays $\left(8.37 \mathrm{eV} /\right.$ channel) in coincidence with ${ }^{210}$ po $\alpha$ particles.

Eig. 10 Lead o $x$-rays (8.37 ev/channel) singles spectrum.

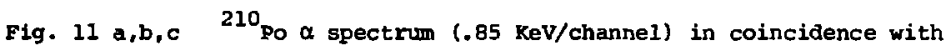
lead $I_{\alpha^{\prime}} \mathrm{L}_{B}$ and $\mathrm{L}_{Y}$ x-rays.

Fig. 11 a,e ${ }^{210}$ Po coincidence $\alpha$ spectrum (.85 KeV/channel).

(d) 210 Po $\alpha$ spectrum in coincidence with solicon $x$-rays whick scattered fram $\alpha$ detector into $y-r a y$ detector.

(e) $210_{\text {Po }} \alpha$ spectrum in coincidencs with lead $M x$-rays.

Fig. 12 Spectroscopic diagram for the major radiative transitions that comprise the characteristic I x-rays spectrum. 
F1g. 13 a,b Varlation of deduced I subshell probabilities as function of $f_{12}$ or $\omega_{2}$.

F1g. $13 \mathrm{crd}$ Variation of deduced $\mathrm{L}$ subshell probabilities as function of $w_{3}$ or $w_{1}$.

Fig. $13 \mathrm{e}, \mathrm{f}$ Variation of deduced subshell probabilities as function of $f_{13}$ or $f_{23}$ 


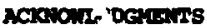

I and indeted to the Iawrenc serkeley Imboratory of the Oniveristy of Calffomia and to the United States Atomic Energy Commisston for the facilities and apport required for this study.

These experiments relied heavily on properly functioning electronic equigment. I an grateful to puane wosier for making the experiments posalble by providing his assistance and advice throughout this study. I grateful to Helen Mlchel for her atient tutelage and help with regard to the chemistry of the radioactive materials used in the experiment. I am also grateful to Eldren Calhoon of the Health Chemistry Division for providing assistance with all matters of handling and safety of radioactive materials.

I an grateful to my advisor, Professor Isadore Perlman, for suggesting the problem to be studied, and most important to Dr. Frank Asaro under whose supervision and constant advice this study was carried out.

Sperial thanks to my wife, Nili, for her interest in my work and her ald in the preparation of this manuscript. 